\title{
Partially Overlapping Ownership and Contagion in Financial Networks
}

\author{
Micah Pollak' and Yuanying Guan² \\ ${ }^{1}$ School of Business and Economics, Indiana University Northwest, 3400 Broadway, Gary, IN 46408, USA \\ ${ }^{2}$ Department of Mathematics and Actuarial Science, Indiana University Northwest, 3400 Broadway, Gary, IN 46408, USA
}

Correspondence should be addressed to Micah Pollak; mpollak@iun.edu

Received 27 July 2017; Accepted 8 October 2017; Published 6 November 2017

Academic Editor: Ahmet Sensoy

Copyright (C) 2017 Micah Pollak and Yuanying Guan. This is an open access article distributed under the Creative Commons Attribution License, which permits unrestricted use, distribution, and reproduction in any medium, provided the original work is properly cited.

\begin{abstract}
Using historical banking data for the United States from the years 2000 to 2015 we characterize the probability and extent of a financial contagion using a calibrated network model of heterogeneous interbank exposures. Both the probability and the average extent of a contagion begin to rise in 2007 prior to the US financial crisis. Including a common asset in the model increases both the probability and extent of contagion, especially during the years of the financial crisis. Based on rising institutional ownership in the banking industry, we introduce a partially overlapping ownership asset that devalues endogenously. The addition of this asset increases the extent of a financial contagion. Our results show that trends in capital buffers and the distribution and type of assets have a significant effect on the predictions of financial network contagion models and that the rising trend in ownership of banks by banks amplifies shocks to the financial system.
\end{abstract}

\section{Introduction}

Following the 2008-2009 US and global financial crisis, there has been a growing interest in the role that the network structure of banks and the types and distribution of their assets have in determining the probability and extent of a potential financial contagion. Chinazzi and Fagiolo [1] provide a concise survey of recent literature in this area. Two limitations common in much of this research relate to the complexity of the network and asset structure and the availability of data. First, the assets and network structures observed in real world financial systems tend to be more complicated than assumed in typical financial network models. Second, detailed data on the structure of real world financial networks is often extremely limited, especially for a major nation like the United States. Empirical papers tend to focus on nations other than the US and often employ data from a single or small number of years. In this paper we improve on these two limitations.

First, in addition to the standard assumption of direct exposures (interbank loans) and independent external assets, we add an external common asset (similar to [2]) and we introduce the concept of a partially overlapping ownership asset, or an asset held by some banks that has value endogenously determined by failures within the banking industry (i.e., such as an investment in an indexed portfolio of stock for the banking industry). In addition to these assets, we consider a core-periphery network structure, which is increasingly becoming the preferred representation of the banking industry. We contrast our results with those from a scale-free network, which is another common network structure. Finally, we use historical financial information for depository institutions in the United States, for the years prior to and following the financial crisis, to calibrate key financial network characteristics such as the size of the network, total assets, and capital buffers for individual banks as well as to characterize and distribute the partially overlapping ownership asset. These steps allow us to investigate how the predictions of a financial contagion model change based on observed trends in the banking industry.

Equity ownership of banks by banks is becoming increasingly common in the United States. Between 2000 and 2015 the number of banks with ownership in other banks doubled in the United States. Over the same time, the total value of 
this ownership across the banking system has been growing, especially following the financial crisis. Between 2011 and 2015 the total value of ownership of banks by banks increased by $211 \%$ (over this same time period the value of the S\&P 500 rose by 55\%). This growth in bank ownership by banks has the potential to add a new and significant feedback channel that amplifies shocks. For example, a negative shock to the banking industry reduces the value of ownership in banks, which, in turn, further negatively affects balance sheets of banks, further reducing the value of bank ownership and adding additional stress to the system. To investigate this trend in institutional ownership, we introduce a partially overlapping ownership asset, to capture the rise in equity ownership of banks by banks, and demonstrate how the addition of this asset amplifies the effects of financial contagions.

Our approach is related to Sensoy's paper [3], in which the author investigates the effects of firm size and ownership structure on commonality in liquidity using unique ownership data for Turkey. The author analyzes both institutional and individual ownership and finds that, in addition to the amount of ownership and firm size, the characteristics of investors, and the microstructure of the market are important in determining systematic liquidity. While related, in our case we focus on the role of institutional ownership in banking networks in order to study financial contagion.

Our results show that for the US banking system between 2000 and 2015 the average capital buffers held by banks increased overall and the probability of contagion declined, with some significant exceptions in 2007 and 2008. Based on a network of direct exposures only, in 2007 and 2008, prior to the US financial crisis, the probability of contagion resulting from the failure of a core bank rose from $19.7 \%$ to $24.6 \%$ (a 24\% increase) and the average extent of a potential contagion more than tripled. The addition of a common asset greatly increases the probability of a contagion in all years, bringing it close to $100 \%$ from a random core bank failure between 2008 and 2010 and close to $100 \%$ in 2009 from a random periphery bank failure. A common asset also more than doubles the average extent of contagion from a core bank failure. While adding a partially overlapping ownership asset increases the probability of contagion from a core bank failure by only about $5 \%$, it doubles the extent of a contagion on average across all years. These results are similar for both core-periphery and scale-free network structures. Before focusing on the data and model we begin with a brief review of literature related to this topic.

Caccioli et al. [4] study the Australian interbank network and show that the interplay of multiple channels of exposures is a major contributor to systemic risk and contagion. They conduct stress tests to analyze contagion through direct exposures, overlapping portfolios, and the combination of these two channels. They conclude that contagion due to counterparty risk can be strongly amplified by the addition of a common portfolio. In another paper, Caccioli et al. [2] extend the analysis of contagion caused by overlapping portfolios to a scenario with multiple assets. They characterize how the average level of diversification in bank portfolios, the ratio of the number of banks to the number of assets, and the leverage attained by banks all affect system stability with respect to an initial shock on a single asset or bank. By conducting analytical simulations on a stylized network (a random network with Poisson degree distributions for both banks and assets), they estimate the region of parameter space where global cascades occur. Poledna et al. [5] analyze a four-layered interbank network and show that a traditional measure of systemic risk based only on a single layer of deposits and loans, which is common in most studies, dramatically underestimates (by as much as 90\%) the risk inherent in a financial system.

While earlier literature provides empirical evidence of real world financial networks following a scale-free network structure [6-8], more recent papers argue that evidence from interbank markets suggest that a core-periphery network structure better represents interbank exposures for various counties, such as for the interbank systems of Netherlands [9], Italy [10], Germany [11], UK [12], Brazil [13], and Mexico [14]. A core-periphery network classifies nodes into two different types: core nodes and periphery nodes. Core nodes are well connected to each other and to periphery nodes, while periphery nodes have connections only with core nodes. Several papers have investigated the core-periphery structure in the context of financial networks, both from a theoretical and dynamic perspective. Lux [15] develops a simple dynamic model of an interbank market where banks initially choose trading partners randomly due to idiosyncratic liquidity shocks. He shows that with heterogeneity in balance sheets and a simple reinforcement learning scheme governing potential trading counterparts, the system quickly converges to a core-periphery network structure. In the paper of van der Leij et al. [16], they propose a simple model of the overnight interbank lending market in which banks compete for intermediation benefits. They find that a complete coreperiphery network is not stable while an incomplete coreperiphery network may be stable with heterogeneity between banks and inequality in payoffs corresponding to inequality in sizes. In their paper, the banks are ex antehomogeneous and they show that heterogeneity plays a key role in forming a stable core-periphery network. Silva et al. [13] bridges the empirical and theoretical literature by developing a method of measuring how close a financial network is to a perfect core-periphery structure and then applying this measure to the Brazilian interbank market.

Galeotti et al. [17] study how financial linkages in networks affect individual payoffs and risk to the system by constructing an ownership matrix and exploring the effects of changes to this network. They find that the effects of integration (strengthening of current links) and diversification (spreading of links to more neighbors) depend crucially on the topology of the network. Specifically, they show that, in a core-periphery network, core banks take more risk than periphery banks, which is consistent with our data, results, and other literatures [9]. They also show that when the network is homogenous, individuals take on too little risk relative to the socially optimal portfolios, while when the network is homogenous, they take on too much risk.

In addition to the empirical literature, which focuses primarily on non-US financial networks, and the theoretical literature, there have been several studies on the structure of 


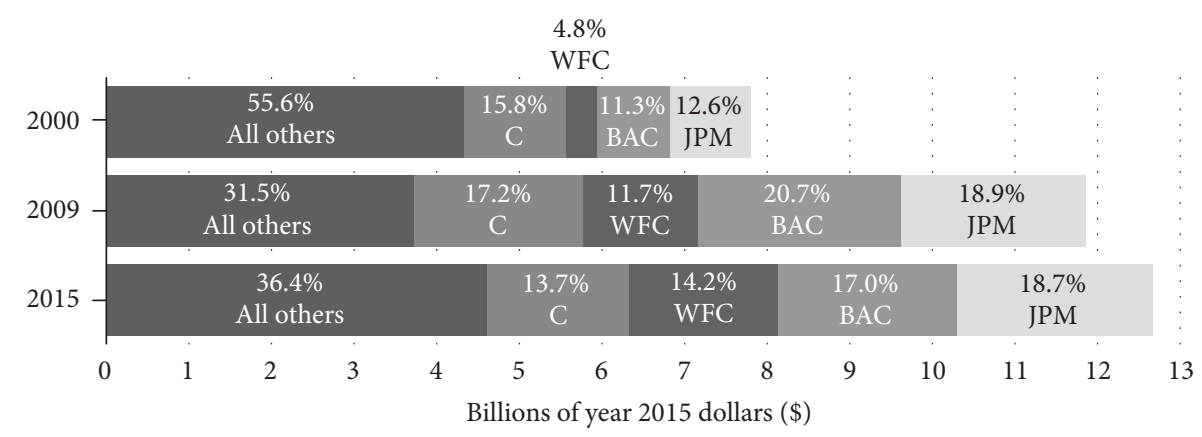

FIGURE 1: Combined total assets and distribution for years 2000, 2009, and 2015 among the largest four banks: JPMorgan \& Chase Co. (JPM), Bank of America Corporation (BAC), Wells Fargo \& Company (WFC), and Citigroup (C).

the US financial market following the financial crisis. McCord and Prescott [18] identify significant changes to the structure of the US banking system after the financial crisis. They find a sharp decline in the number of banks, mostly among smaller banks. They provide evidence that this decrease is not due to more banks exiting the market, but rather to a decline in the number of new entries. They also find trends in asset concentration which are consistent with our data. While we focus on banks with $\$ 1$ billion or more in total assets, Kowalik et al. [19] studied mergers of US banks with $\$ 1$ billion or less in total assets following the financial crisis. They also find a decline in the number of banks and argue that since the end of the recession, voluntary mergers have been the main reason for this decline. They find that larger banks tend to acquire smaller banks in order to more quickly expand loan operations and gain access to cash and deposits to support future loan growth.

The rest of this paper is organized in the following way. Section 2 presents data from 2000 to 2015 on the US banking system and discusses key trends in the number of banks, total assets, capital buffers, and equity ownership. Section 3 explains the underlying model, network algorithm, and calibration to the observed data. Section 4 presents the results based on different combinations of the three assets types: direct exposures, a common asset and a partially overlapping ownership asset. Section 5 provides a brief summary of our results and some concluding remarks.

\section{Data}

Our data are based on balance sheet and ownership information from the FactSet Fundamentals database for the years 2000 to 2015 or approximately seven years before and after the 2008/2009 US financial crisis. We restrict our attention to firms (henceforth "banks") classified as depository credit intermediation institutions (NAICS code 5221) and headquartered in the United States and with total assets exceeding \$1 billion in year 2015 dollars (adjusted for inflation using the Bureau of Labor Statistics' Consumer Price Index for all urban consumers, US city average series for all items). Between 2000 and 2015 there are a total of 696 banks that satisfy this criteria with an average of 361 active banks in a given year. These data represent an unbalanced panel in which institutions may enter and exit the sample based on mergers, acquisitions, and bankruptcies. A large proportion of institutions, 145 out of the average 361 or $40 \%$ in a given year, are active and filed financial statements across all 16 years. While a complete analysis of the structure of the US banking system is beyond the scope of this paper (for a more detailed characterization of some of changes to the US banking system over this time see $[18,19])$, we focus on major trends in the number of banks, size and distribution of total assets, changes in capital buffers, and trends in ownership of other banks.

Table 1 presents the summary statistics for number of banks, total assets adjusted for inflation and capital buffers. The total number of banks in the data peaks in 2003 at 390 declines to a low of 333 in 2012 consistent with $[18,19]$ and then returns by 2015 to roughly the same level as in 2000 .

Between 2000 and 2015 mean total assets rose consistently, growing $63.3 \%$ (3.3\% on average annually). Over the same time period, median total assets generally declined until 2009 before rising again for a total growth between 2000 and 2015 of $17.1 \%$ (1.1\% on average annually). The large difference between mean and median is driven primarily by three outliers. Between 2000 and 2015 the assets of Wells Fargo \& Company grew by $\$ 1.43$ trillion $(+385 \%)$, JPMorgan Chase \& Co. by $\$ 1.39$ trillion $(+142 \%)$, and Bank of America Corporation by $\$ 1.27$ trillion $(+144 \%)$. The growth of these banks is primarily the result of consolidation in the years leading up to and during the 2007/2008 financial crisis (among the most significant were the 2004 mergers of Bank One Corporation with JPMorgan \& Chase Co. and FleetBoston Financial Corporation with Bank of America Corporation and then in 2008 the purchase of Washington Mutual out of seizure by JPMorgan \& Chase Co. and the acquisition of Wachovia Corp. by Wells Fargo). This can also be seen in Figure 1, which shows the combined total assets in the data, highlighting the largest four banks, for the years of 2000, 2009, and 2015. These data show extreme consolidation and growth among the four largest banks up to and during the US financial crisis. In 2000 the four largest banks owned $44.4 \%$ (or $\$ 3.46$ billion) of all assets in the system, in 2009 this grew to $68.5 \%$ (or $\$ 8.12$ billion), and in year 2015 they owned $63.6 \%$ (or $\$ 8.06$ billion).

2.1. Trends in Capital Buffers. Table 1 also shows summary statistics by year for capital buffers. Consistent with Gai 


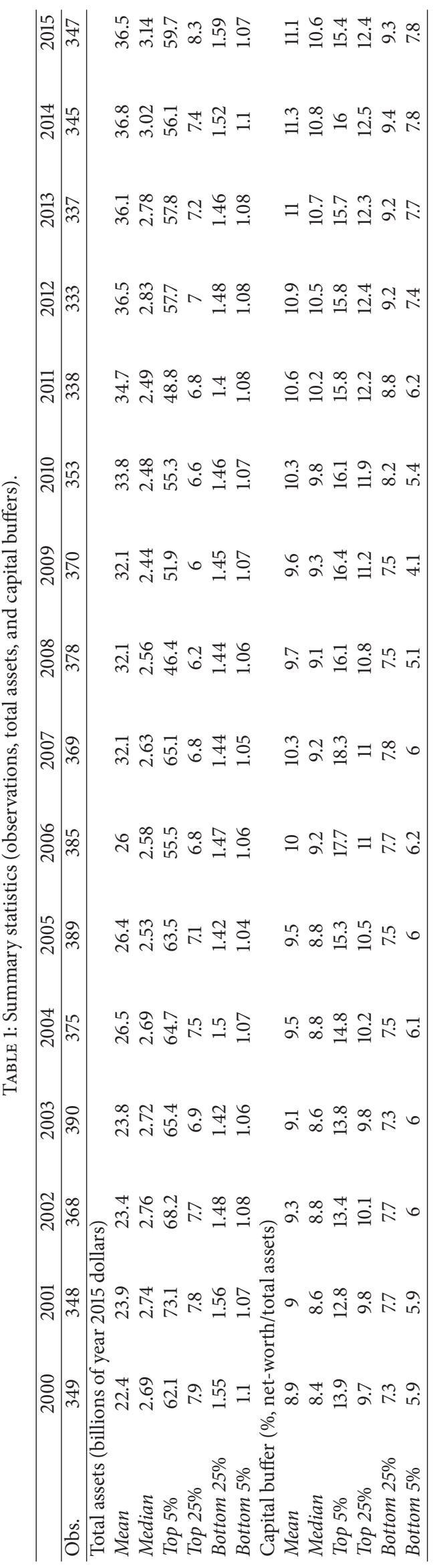




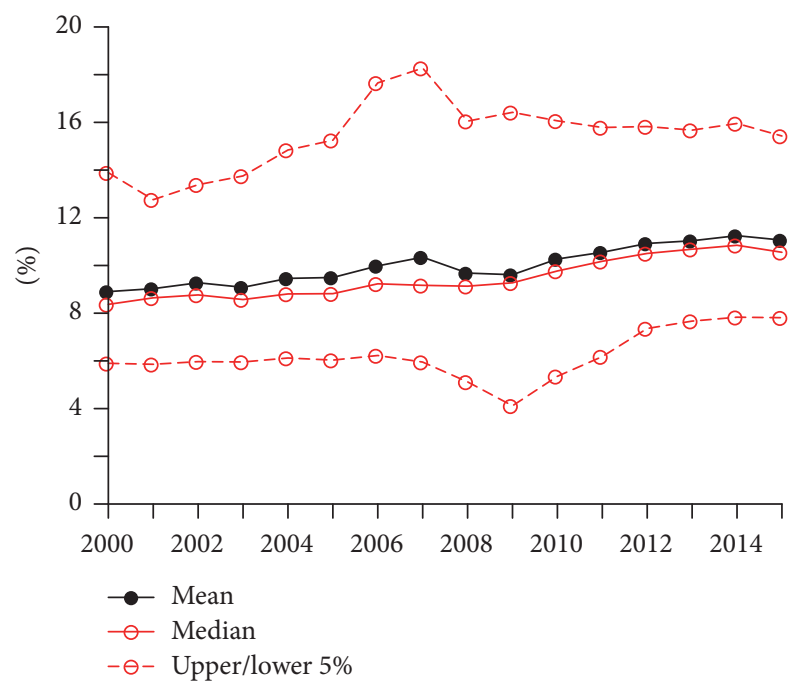

Figure 2: Capital buffer levels by year (as a percent of total assets).

and Kapadia's specification in [20] we define an institution's capital buffer as their net-worth (total assets minus total liabilities) divided by total assets. Capital buffers show a trend similar to mean total assets and are generally increasing, from a mean of $8.9 \%$ in 2000 to $11.1 \%$ in 2015 . The overall rise in capital buffers is likely in part due to the tightening of the Basel Accords during this time (see Appendix A for discussion on the role of the Basel Accords over this time period). One significant exception to the trend occurs in 2007 and 2008 just before the US financial crisis and can be seen in Figure 2. Mean capital buffers fell from 10.3\% in 2007 to $9.7 \%$ in 2008 and for the highest $5 \%$ percentile, capital buffers declined from $27.2 \%$ to $22.8 \%$. For banks in the lowest $5 \%$ percentile of capital buffers these buffers declined from $6.0 \%$ in 2007 to $5.1 \%$ in 2008 to $4.1 \%$ in 2009 . The sharp decline during 2007 and 2008 for these lowest 5\% of banks will play an important in our results, as the definition of a financial contagion is when at least $5 \%$ of banks in the system fail. Based on this definition, in 2009 an exogenous loss of just over $4 \%$ of total assets at these banks (ignoring any subsequent losses due to direct exposures and other common and overlapping assets) would alone be sufficient to trigger a contagion. Following 2009, mean and median capital buffers begin to climb again. Figure 2 shows this trend in capital buffers over time. There is a weak correlation between total assets and capital buffers that is negative from 2000 to 2006 and positive from 2007 to 2015 this correlation is statistically significant at the $5 \%$ level and negative in years 2000 and 2001 and positive in years 2011, 2012, and 2015, based on an OLS regression of capital buffer $=\alpha+\beta \log$ (Total Assets). In year 2000 a $100 \%$ increase in total assets results in a 0.25 percentage point decrease in capital buffer while in year 2015 a $100 \%$ increase in total assets results in a 0.27 -percentage point increase in capital buffer. This suggests that prior to the US financial crisis larger banks tended to carry relatively smaller capital buffers and after the crises relatively larger buffers.
TABLE 2: Number of banks with ownership and average ownership (as a percent of total assets) by bank size in 2015 .

\begin{tabular}{lccc}
\hline $\begin{array}{l}\text { Total Assets } \\
\text { Range }\end{array}$ & $\begin{array}{c}\text { Banks } \\
(\#)\end{array}$ & $\begin{array}{c}\text { Owner-banks } \\
(\#)\end{array}$ & $\begin{array}{c}\text { Mean share of } \\
\text { assets }\end{array}$ \\
\hline \$100 billion+ & 14 & 5 & $0.47 \%$ \\
\$10-100 billion & 54 & 12 & $0.30 \%$ \\
\$5-10 billion & 60 & 10 & $1.16 \%$ \\
Under \$5 billion & 219 & 17 & $2.24 \%$ \\
\hline
\end{tabular}

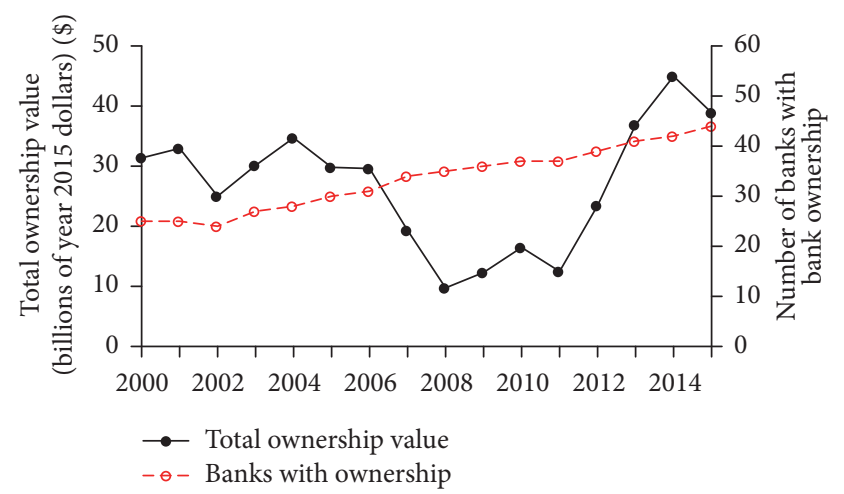

FIgURE 3: Trends in bank ownership in other banks. Total value of ownership in billions of year 2015 dollars (left axis) and number of owner-banks (right axis) by year.

2.2. Trends in Ownership and Owner-Banks. In addition to balance sheet information, we collect equity ownership data for each bank from the FactSet Fundamentals database. We then match this ownership data to the banks in our data to construct a matrix of bank equity ownership in other banks. To simplify discussion, banks with ownership in other banks will be referred to as "owner-banks." Between 2000 and 2015 there was a marked increase in both the number of ownerbanks and the total value of that ownership. In the year 2000 , there were 25 banks with ownership in other banks that totaled \$31.3 million in value. By year 2015 there were 44 banks with ownership that totaled $\$ 38.9$ million.

The increase in the total value of ownership is especially pronounced since the end of the financial crisis. Between 2011 and 2015 the total system value of bank ownership by ownerbanks increased from $\$ 12.5$ billion to $\$ 38.9$ billion (a $211 \%$ increase). Figure 3 shows the total value of ownership within the system and the number of owner-banks. While some of this increase can be attributed to the rise in the stock market (the S\&P 500 rose $55.1 \%$ over the same period), this only explains a small portion of the increase in ownership value and does not explain the sustained increase in the number of owner-banks (between 2008 and 2015 the total value of bank ownership increased by $299 \%$ while the S\&P 500 rose only $44.7 \%)$.

While ownership in other banks is more likely among larger banks, it is not exclusive to them. Table 2 shows for year 2015 the number of owner-banks and the proportion of owner-bank total assets in ownership, broken down by various sizes of total assets. Of the 14 largest banks (those 
with over $\$ 100$ billion in total assets) five were owner-banks. For these five, the mean value of this ownership was equal to $0.47 \%$ of their total assets. For smaller banks, those with total assets between $\$ 5$ and $\$ 10$ billion and those with assets below $\$ 5$ billion, the value of their ownership, as a proportion of total assets, was much higher (1.16\% and $2.24 \%$, resp.). Thus, investing in ownership of other banks is not limited to large banks, and smaller banks leverage a larger portion of their assets in bank ownership.

For most owner-banks this ownership is relatively diversified. For example, in 2015 owner-banks had, on average, ownership in over 27 other banks (median 12.5), with larger banks generally having ownership in a larger number of other banks. Owner-banks also tend to limit their exposure to ownership in a single bank, with the average owner-bank in 2015 investing at most $40 \%$ of their ownership assets in a single bank. In 2015, the average ownership amount per bank was $12 \%$ of their total ownership value. There are similarities in the banks that owner-banks choose to invest in. In 2015, more than half of total system ownership value was in just two banks, (33\% of the total system ownership value was in Bank of America and $17.7 \%$ in Wells Fargo). In addition, out of the 44 owner-banks, 42 have a share of ownership in Wells Fargo, 40 in JPMorgan, and 33 in US Bank. As a result, the failure of any of these highly owned banks would have a significant effect on the value of ownership assets across the system.

Overall, ownership of banks by banks still represents a relatively small portion of total assets. In 2015, for the ten banks with the largest ownership positions (as a percent of total assets) represented on average only $3.6 \%$ of their total assets and across all owner-banks in 2015 the average value of ownership was only $1.26 \%$ of total assets. While investment in bank ownership is a relatively small asset class, it is growing. Furthermore, there may be significant ownership through private equity and debt that we cannot easily observe. The growth of bank ownership by banks is potentially concerning given that it has the potential to feedback into and amplify any shocks to the banking industry.

\section{Model and Methods}

The model we use in our analysis is based on Gai and Kapadia's model from [20], with the addition of heterogeneous link-weights as in [21] and a common asset as in [4]. We also introduce a new type of asset, a partially overlapping ownership asset, which is held by only some banks and has value affected endogenously by bank failures. We begin by going over the details of the model and assets before discussing the generation of the financial network, calibration to US banking data, and the method behind the financial contagion simulations.

3.1. Banks and the Financial Environment. Assume that there are $N$ financial institutions (banks) in a network and each bank is represented by a node in the network. Let $A_{i}^{\text {TOT }}$ and $L_{i}^{\text {TOT }}$ be the total assets and liabilities for bank $i$. Each bank holds interbank assets, $A_{i}^{I}$, as well as some combination of a common asset, $A_{i}^{C}$, a partially overlapping ownership asset,
$A_{i}^{O}$, and other external assets, $A_{i}^{M}$. Each bank has two types of liabilities, customer deposits, $D_{i}$, and interbank liabilities, $L_{i}^{I}$. If a bank becomes insolvent at any point (i.e., $A_{i}^{\mathrm{TOT}}<L_{i}^{\mathrm{TOT}}$ ) it immediately fails and defaults on its interbank liabilities. The value of any interbank assets at a failed bank becomes zero.

The financial network is defined by a network of interbank lending and borrowing. Let $A \subset \mathscr{R}_{+}^{2}$ be $N$ by $N$ matrix that represents the network of interbank exposures. Each element $a_{i j}$ represents the amount of assets bank $i$ loans to bank $j$. By convention, $a_{i i}=0$. Therefore $A_{i}^{I}=\sum_{j=1}^{N} a_{i j}$ is the total interbank lending by bank $i$ and $L_{i}^{I}=\sum_{j=1}^{N} a_{j i}$ is the total interbank borrowing of bank $i$. Matrix $A$ represents a weighted directed network with heterogeneous link-weights. Incoming links of a node reflect the interbank assets of the node. Outgoing links of a node represent the interbank liabilities of that node. Let $w_{i j}=a_{i j} / A_{i}^{I}$ be the proportion of interbank assets belonging to bank $i$ held by bank $j$.

In addition to interbank assets, each bank invests its remaining assets across a combination of a common asset, a partially overlapping ownership asset and external assets. The risks and exposures associated with each of these assets are different. The common asset reflects an asset held by all banks with a common value determined exogenously (e.g., mortgage-backed securities). The common asset decreases in value only due to an exogenous shock, however, any decrease in value will affect the balance sheets of all banks.

The partially overlapping ownership asset reflects equity ownership in a portfolio of banks within the system and may decline in value following the failure of any bank included in the portfolio. Unlike the common asset, neither do all banks hold the partially overlapping ownership asset, nor all banks hold necessarily included in the portfolio. The partially overlapping ownership asset can be interpreted as a single investment fund indexed to select banking stocks. The network of ownership generated by this asset can be thought of as a second, completely distinct, structure from the network of interbank exposures. In a given year, we define the share of this portfolio invested in bank $j$ as $P_{j}$. If bank $j$ fails, then the value of its stock falls to zero and the partially overlapping ownership asset will devalue to reflect this or suffer a $1-P_{j}$ loss. This loss, in turn, is reflected in the value of the partially overlapping ownership asset held by some banks. All banks that choose to invest in the partially overlapping ownership asset purchase the same portfolio.

Finally, any remaining assets not invested in interbank assets, the common asset or the partially overlapping ownership asset, are invested in a risk-free external asset. This external asset represents other assets outside the scope of the model.

Our main interest is in determining the probability and extent of a financial contagion stemming from a single shock to the financial system. All scenarios we study begin by imposing the failure of a random bank on the financial network. In scenarios in which the common asset is present, we simultaneously impose an exogenous shock of size $\phi$ to this common asset in addition to the initial failure of a random bank. Following this initial failure (and possibly 
the decline in value of the common asset), the shock may then be transmitted across the financial network through two channels. First, the failure and default of the initial bank will eliminate any interbank assets of other banks held at this bank. Second, if the failed bank is contained in the portfolio of the partially overlapping ownership asset then the value of this asset will decline for banks holding this asset. These two effects combine to eliminate or reduce the value of assets for some banks across the network, which in turn may cause additional banks to fail.

To formalize the condition under which bank $i$ fails following the initial failure of another bank (and possible simultaneous devaluing of the common asset) let $K_{i}=A_{i}^{\mathrm{TOT}}-$ $L_{i}^{\mathrm{TOT}}=\left(A_{i}^{I}+A_{i}^{M}+A_{i}^{C}+A_{i}^{O}\right)-\left(L_{i}+D_{i}\right)$ represent the capital buffer of bank $i$. Following an initial failure of bank $j$, the solvency condition for bank $i$ is

$$
\begin{aligned}
L_{i}+D_{i}< & A_{i}^{M}+\left(1-w_{i j}\right) A_{i}^{I}+(1-\phi) A_{i}^{C} \\
& +\left(1-P_{j}\right) A_{i}^{O}
\end{aligned}
$$

and bank $i$ will fail if

$$
w_{i j}>\frac{K-\phi A_{i}^{C}-P_{j} A_{i}^{O}}{A_{i}^{I}} .
$$

Should bank $i$ fail, they then default on their interbank liabilities and the partially overlapping ownership asset may devalue. This process continues (with the solvency condition updated to reflect prior failures) until no further banks fail.

Consistent with [20], if over $5 \%$ of all banks in the system fail then we define this as a financial contagion. The extent of such a financial contagion is defined as the proportion of banks that fail or the expected proportion of banks that fail conditioned on at least $5 \%$ of banks failing.

3.2. Calibration and Simulation Methods. For each year we begin by calibrating the number of banks, as well as the total assets and total liabilities for individual banks to the observed data. The private nature of interbank loans in the United States means that data on the structure of the interbank asset network is limited. As a result, for each year we simulate 100 core-periphery network structures to represent the network of interbank assets, using an algorithm calibrated to match the typical characteristics of the interbank market of other nations (while 100 simulations may seem low, because assets and liabilities of individual banks are drawn directly from the data and because the network generation algorithm is based in part on these data, it is sufficient to allow our results to converge. Increasing simulations to 1000 per year does not have a significant effect on our results). See Section 3.3 for additional details on the algorithm and parameters used to generate the network.

While the network of interbank exposures is based on underlying balance sheet data, the partially overlapping asset is generated from separate data on the equity ownership of banks by banks that is not directly related to interbank exposures (for a brief discussion of when exposures from ownership may be equivalent to exposures from interbank lending and when it is appropriate to treat these as two distinct assets see Section 5). To generate the partially overlapping ownership asset, in each year we construct a single asset that reflects a representative portfolio of all observed ownership in banks. The share of this portfolio invested in bank $j$ is equal to the total value of equity ownership by all banks in bank $j$ as a fraction of the total value of equity ownership by all banks in all other banks, which can be expressed as $P_{j}=\sum_{i=1}^{N}\left(\widehat{P}_{i j} / \sum_{k=1}^{N} \widehat{P}_{i k}\right)$, where $\widehat{P}_{i j}$ is the observed dollar value of ownership held by bank $i$ in bank $j$. After constructing the ownership asset portfolio $P=\left\{P_{1}, P_{2}, \ldots, P_{N}\right\}$, we then distribute the amount of assets; we observe each bank investing in equity ownership to this portfolio.

For owner-banks or those banks which we observe having ownership assets in the data, we multiply the amount of the observed ownership, or $A_{i}^{O}=\sum_{i=1}^{N} \widehat{P}_{i j} / A_{i}^{\mathrm{TOT}}$, by a factor of 15 , capped at $40 \%$ of their total assets. The factor of 15 was chosen to increase the average ownership by owner-banks to be equal to approximately $20 \%$ of total assets or half of the proportion we assign to the common asset (the observed ownership by owner-banks as a percent of their total assets in 2015 was equal to $1.26 \%$ on average. See Section 2.2 for more details). Banks that we observe having no assets in equity ownership invest zero in the ownership asset. We use this form of a representative portfolio of ownership, rather than the observed ownership network structure, and amplify the value of this ownership, to reflect the possibility of other unobserved sources of ownership, such as private equity and debt ownership, as well as to more clearly capture the effect of this asset class on financial contagions.

In the results presented in Section 4 we consider four scenarios. In all four scenarios each bank holds $20 \%$ of their total assets in interbank assets $\left(A_{i}^{I}=0.2 A_{i}^{\mathrm{TOT}}\right)$ and the differences are in how the remaining $80 \%$ of total assets are invested. The four scenarios are as follows:

(1) Direct exposures only: in Section 4.1 we first consider the simplest case with only direct exposures from interbank assets $\left(A_{i}^{C}=A_{i}^{O}=0\right)$.

(2) Common asset: next, in Section 4.2, in addition to direct exposures, we add a common asset equal to $40 \%$ of total assets to all banks which depreciates by $10 \%$ simultaneously with the initial shock $\left(A_{i}^{\mathrm{C}}=\right.$ $\left.0.4 A_{i}^{\mathrm{TOT}}, A_{i}^{\mathrm{O}}=0\right)$.

(3) Partially overlapping ownership asset: in Section 4.3 instead of the common asset, we add to direct exposures the partially overlapping asset, which is held by some banks and may reflect up to $40 \%$ of their total assets $\left(A_{i}^{C}=0,0.4 A_{i}^{\mathrm{TOT}} \geq A_{i}^{\mathrm{O}} \geq 0\right)$.

(4) Common and partially overlapping ownership assets: finally, in Section 4.4 we consider the combined effects of these assets by combining the partially overlapping asset with the common asset $\left(A_{i}^{\mathrm{C}}=\right.$ $\left.0.4 A_{i}^{\mathrm{TOT}}, 0.4 A_{i}^{\mathrm{TOT}} \geq A_{i}^{\mathrm{O}} \geq 0\right)$.

In each scenario, any assets not invested in direct exposures (interbank assets), the common asset or the partially 
TABLE 3: Comparing the CP model for the Dutch interbank market to Germany (Craig and Von Peter, 2014 [11]), Italy (Fricke and Lux, 2014 [10]), UK (Langfield et al., 2014 [12]), and Mexico (Solis-Montes, 2013 [14]).

\begin{tabular}{|c|c|c|c|c|c|}
\hline Country & Netherlands & Germany & Italy & UK & Mexico \\
\hline The number of banks & 100 & 1800 & 120 & 176 & 46 \\
\hline Average number of core banks & \pm 15 & \pm 45 & \pm 30 & 16 & \pm 16 \\
\hline Average core size & $\pm 15 \%$ & $\pm 2.5 \%$ & $\pm 25 \%$ & $9.1 \%$ & $\pm 35 \%$ \\
\hline Error frequency, as \% of links & $29 \%$ & $12 \%$ & $42 \%$ & $47 \%$ & $25 \%$ \\
\hline
\end{tabular}

overlapping ownership asset, are invested in other external assets $\left(A_{i}^{M}\right)$.

3.3. Network Structure. To generate the network of interbank exposures we follow the definition of a core-periphery network in in't Veld and van Lelyveld [9] and van der Leij et al. [16].

Definition 1. A network is a perfect core-periphery network if there exists a set of core nodes $K \subset N$ and periphery nodes $P=N \backslash C$ such that

$$
\begin{aligned}
& g_{i j}=1, \\
& g_{j i}=1, \\
& \quad \forall i, j \in K, \\
& g_{i j}=0, \\
& g_{j i}=0, \\
& \quad \forall i, j \in P, \\
& g_{i j}=1, \quad \forall i \in K, \quad \exists j \in P, \\
& g_{h i}=1, \quad \forall i \in K, \quad \exists h \in P,
\end{aligned}
$$

where $g_{i j}$ represents a directed link between nodes $i$ and $j$. This defines a perfect directed core-periphery network.

If we form a network of interbank assets as a perfect coreperiphery structure, using the matrix $A$ to represent the links between different banks, we will get

$$
A=\left[\begin{array}{ll}
C C & C P \\
P C & P P
\end{array}\right]=\left[\begin{array}{cc}
1 & C P \\
P C & 0
\end{array}\right] .
$$

A number of recent papers [9-14] find that real financial networks exhibit a similar structure to a perfect coreperiphery networks, only with the addition of link "errors." These "errors" are missing links between core nodes as well as extra links between periphery nodes. Table 3 represents data from in't Veld and van Lelyveld [9] characterizing the number of core banks and error frequency of banking systems in different countries.

To simulate a network of interbank exposures to reflect the US banking system we first we assume that core banks are those banks with the highest total assets in the system. We fix the number of core banks at 25 , which is the average number of core banks across the countries in Table 3. After constructing the perfect core-periphery bank network, we calibrate error links. The error frequency of our network is set at $31 \%$, which is the average of error frequencies of different countries in Table 3.

In addition to simulating the network of interbank exposures as a core-periphery network structure, we also consider a scale-free structure as in [21] and find results very similar to that of the core-periphery structure. The algorithm to generate the scale-free network as well as the results can be found in Appendix B.

\section{Results}

The results in this section are organized into subsections in which we sequentially introduce each asset type. Section 4.1 begins with only direct exposures through interbank lending. Section 4.2 adds a common asset owned by all banks and Section 4.3 adds a partially overlapping ownership asset to direct exposures. Finally, Section 4.4 adds the combination of a common asset and a partially overlapping ownership asset to direct exposures. When a common asset is present we present contagion results from both the initial failure of a random core node and the initial failure of a random periphery node. In the absence of a common asset, contagions do not result from the initial failure of any periphery nodes and only the results from an initial core node failure are given (in the cases where the initial failure of periphery nodes does not result in a contagion the overall contagion probability (resulting from the initial failure of any node) can be determined by multiplying the probability of contagion from a core node failure by the proportion of nodes that are core nodes, or $25 / \mathrm{N}$, which is equal, on average, to 0.069 ). In addition, we restrict our focus to the core-periphery network structure, as it is more representative of the US banking system. The results for the scale-free network structure are extremely similar and for the complete results for the scalefree network structure see Appendix B.

4.1. Direct Exposures Only. As a baseline case we begin by considering the possibility of a financial contagion arising only through direct exposures to counterparties through interbank lending. The approach was first developed in [20] and then expanded in $[21,22]$. Network characteristics such as the number of nodes, the total assets of each node, and the capital buffer of each node are calibrated from data on the US financial system and interbank exposures are generated with a core-periphery network structure (see Sections 3.2 and 3.3 for further details). Our main results are that, with the calibrated data for the US financial system and only 


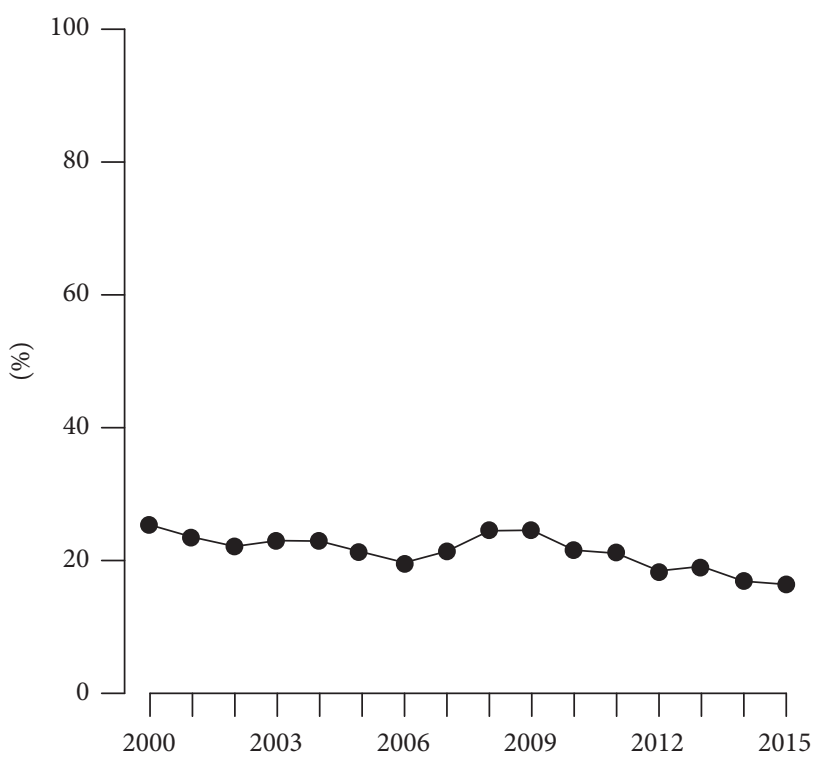

(a) Contagion probability (core node)

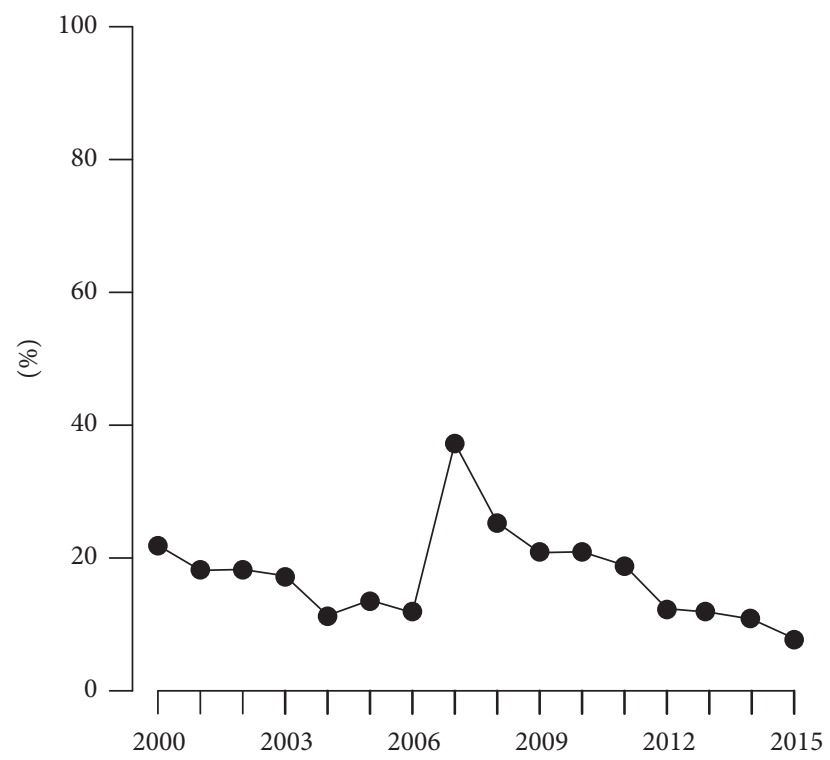

(b) Contagion extent (core node)

Figure 4: Contagions with Direct Exposures Only. Probability (a) and extent (b) of a financial contagion for a core-periphery network with direct exposures only, conditioned on a random core bank failing.

direct exposures, financial contagions originate only from the failure of core banks and that there was a significant increase in the probability and extent of a financial contagion beginning in 2007, prior to the US financial crisis.

With only direct exposures, financial contagions begin only with the initial failure of a core node or the failure of one of the largest 25 banks. Due to the concentration of lending at core nodes and their greater connectedness, the failure of a single core node will have greater and wider-reaching implications than the failure of a periphery node. Figure 4 shows the simulated probability of contagion (a) and average extent of contagion (b) based on the initial failure of a random core node.

Overall between 2000 and 2015 the probability of a financial contagion resulting from the failure of a random core node generally declined (from $25.4 \%$ to $16.4 \%$ ). A significant exception was in 2007 , when the probability rose from $19.7 \%$ to $21.4 \%$, and 2008 , when it rose to $24.6 \%$, prior to the beginning of the US financial crisis (the US financial crises are often marked as beginning with the bankruptcy of Lehman Brothers in September 2008. The effect in 2007 is also present and more pronounced in the scale-free model, where the probability of contagion rose from $17.6 \%$ to $19.5 \%$ in 2007). This rise in the probability of contagion is accompanied by a more than tripling in the average contagion extent in 2007 , from $11.8 \%$ to $37.3 \%$. Viewed ex post, these results can be interpreted as a significant warning sign in 2007 of the coming financial crisis. The results from the scale-free network structure (see Appendix B) are similar.

While the rise in probability and extent of a financial contagion in 2007 and 2008 are consistent with the financial crisis, the result that an initial failure of a periphery node never leads to a financial contagion suggests that direct exposures through interbank lending alone may not provide a rich enough set of exposures to explain more than a small class of extreme financial contagions. To address this, in the next sections we consider additional types of assets and exposures.

4.2. Common Asset. In this section we add a common asset, in a manner consistent with [4], to the existing direct exposures. This common asset provides an additional exposure common to every bank, which increases the chance of a financial contagion. Consistent with the results of [4], we find that the addition of a common asset to direct exposures significantly increases both the probability and extent of financial contagions. Unlike the previous case in Section 4.1 with direct exposures only, during some years the probability of contagion from the initial failure of periphery node is positive.

Figure 5 shows the simulated probability of contagion from the failure of a random core node (a) and a random periphery node (b) as well as the average extent of contagion for each type of initial failure ((c) and (d), resp.). Included in each figure in red for comparison are the results from Section 4.1 for direct exposures only.

With the addition of a common asset, the probability that the failure of a core node triggers a contagion is both extremely high and highly volatile (Figure 5(a)), especially beginning in year 2008 and through the years of the US financial crisis. The probability of contagion drops from $82 \%$ in 2000 to $47 \%$ in 2006 before jumping to $99 \%$ in 2008 and then eventually dropping to $39 \%$ in 2015 . While this probability may appear extremely high, recall that it is conditioned on the failure of a core node or one of the 25 largest banks. The overall probability of contagion resulting from the initial failure of any random node (core or periphery) for year 2000 is just $5.9 \%$. 


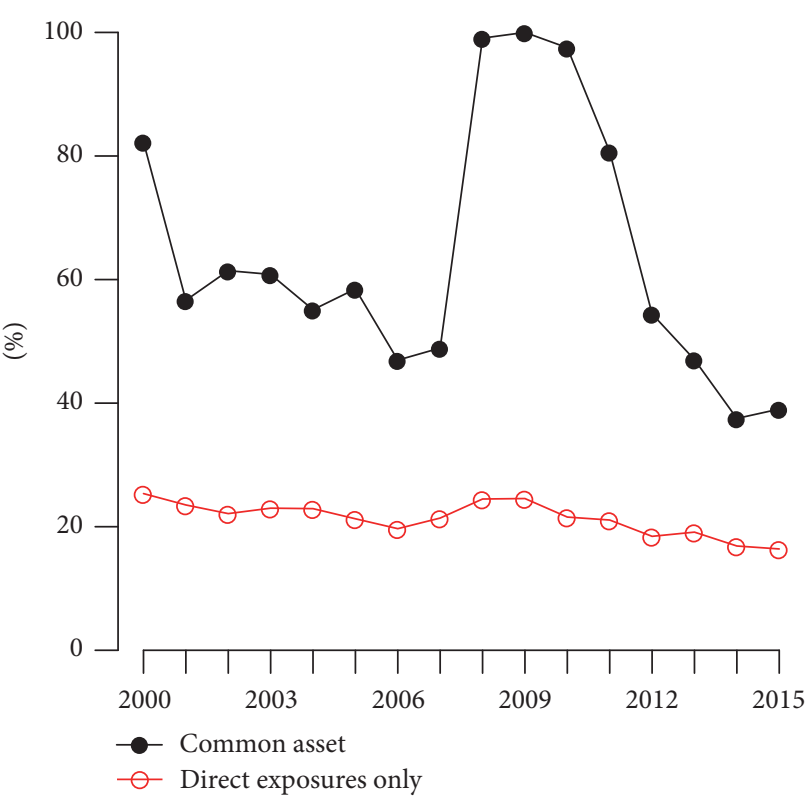

(a) Contagion probability (core node)

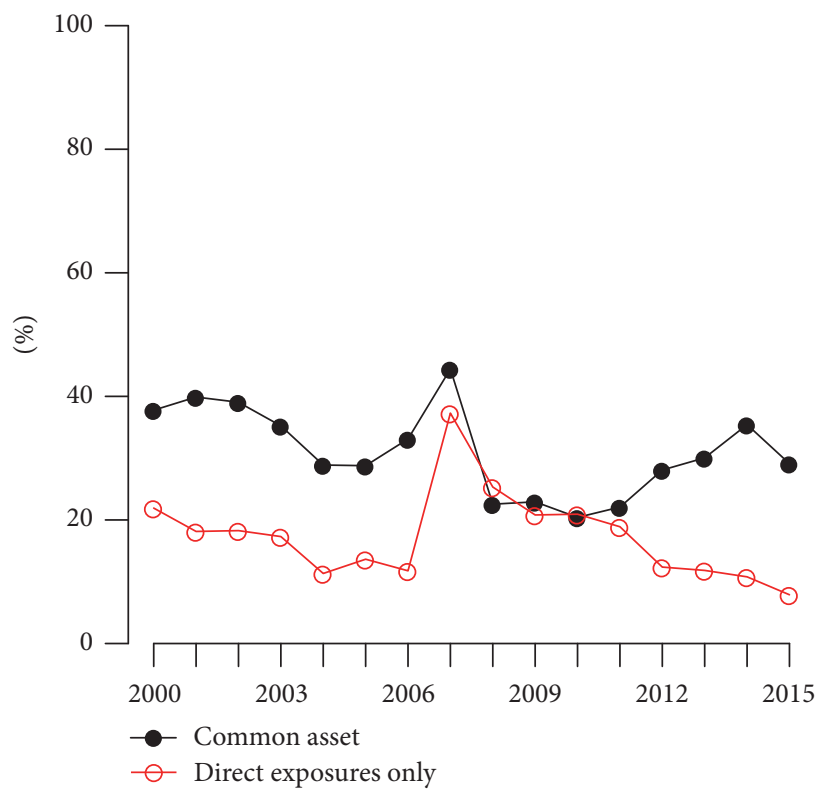

(c) Contagion extent (core node)

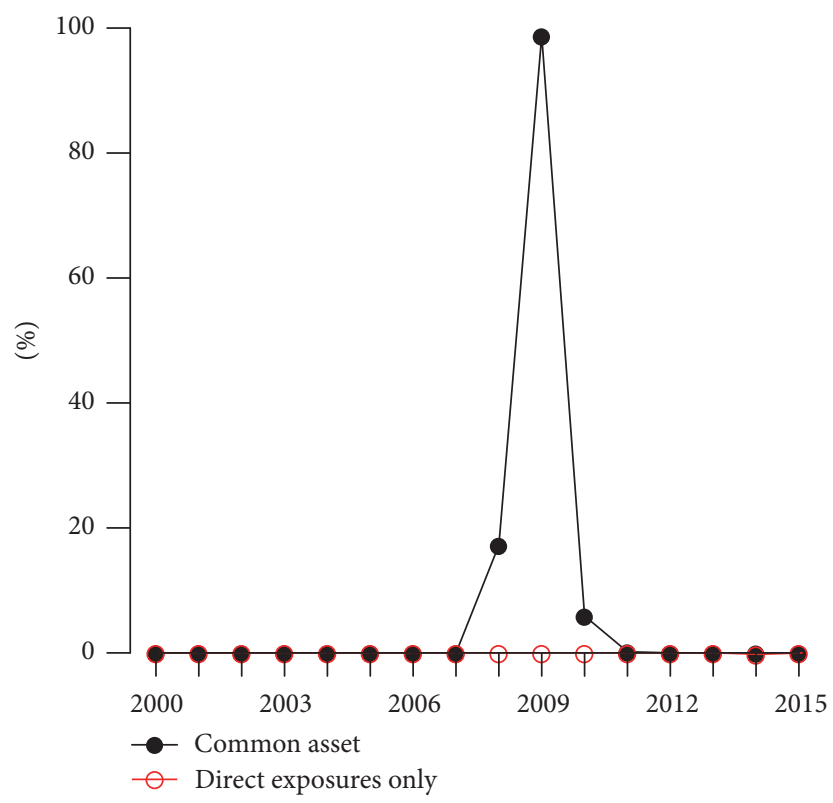

(b) Contagion probability (periphery node)

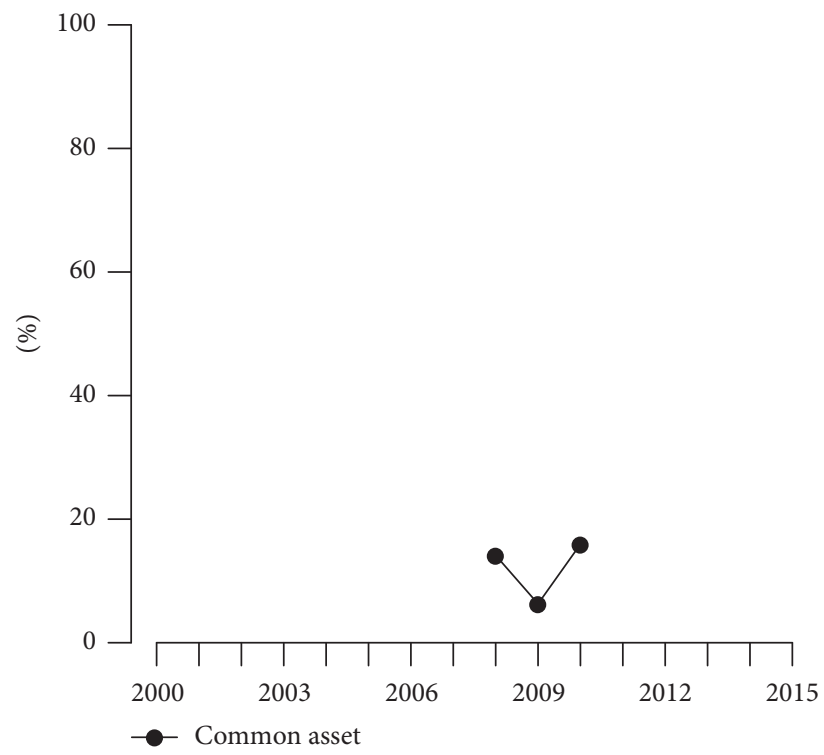

(d) Contagion extent (periphery node)

Figure 5: Contagions with a Common Asset. Probability of a contagion ((a) and (b)) and average extent of contagion ((c) and (d)) for a coreperiphery network with a common asset and direct exposures (black solid circles) and direct exposures only (red empty circles) conditioned on a random core bank failing ((a) and (c)) and conditioned on a random periphery bank failing ((b) and (d)). Contagion extent shown only when average contagion frequency is greater than $1 \%$.

The addition of a common asset also greatly increases the average extent of a financial contagion stemming from the failure of a core node for most years (Figure 5(c)). Between years 2000 to 2006 and 2012 to 2015 the contagion extent from a core node failure is 15 to 25 percentage points higher with the addition of a common asset. During 2007 to 2011, the years leading up to and during the financial crisis, the average extent is the same with and without a common asset, due to a large increase in the number of smaller contagions, which is discussed further below.
In addition to significantly increasing the probability and extent of a contagion resulting from the failure of a core node, the addition of a common asset introduces the possibility of a contagion from a periphery node, although only during the immediate years of the financial crisis. Prior to 2008 and after 2010 the probability of a contagion from a periphery node is zero (Figure 5(b)). In 2008 this probability rises to $17.2 \%$, then to $98.7 \%$ in 2009 before falling to $5.9 \%$ in 2010 . Combined with the results for the core node failures, in 2009 the probability of a contagion resulting from the failure of any 
single node (core or periphery) was $98.9 \%$, or a near certainty. However, this near certainty of a contagion is offset by an extremely low contagion extent for periphery node failures (Figure 5(d)). In 2009, the average extent of a contagion resulting from the failure periphery node was only $6.3 \%$.

The extremely high probability of contagion in 2009 for both core and periphery nodes is being primarily driven by the decline in capital buffers we observe in the data among banks with the lowest capital buffers. In 2009 the $5 \%$ of banks with the lowest capital buffers (see Figure 2 and Table 1) had capital buffers at or below $4.1 \%$. Since the exogenous depreciation of the common asset can be interpreted as a four-percentage point loss in total assets this depreciation alone results in the failure of a significant number of nodes. During most years the initial depreciation of the common asset results in between 0 and 3 failures directly (i.e., before the failure of a random node and the spread of the shock through direct exposures). However, in 2009 due to low capital buffers this depreciation of the common asset directly results in the failure of 17 nodes ( $4.59 \%$ of the network). Combined with our imposed failure of one node, only one additional node needs to fail through interbank exposures in this year to meet the definition of a contagion. As a result of the decline in capital buffers a financial contagion is almost guaranteed with a common asset in 2009; however, the extent of such a contagion may be relatively small. This result also explains the convergence of contagion extent we see for core node failures in 2008, 2009, and 2010.

While for most years the average contagion extent from a core node failure with a common asset is 15 to 25 percentage points higher than with direct exposures only, between 2008 and 2010 this extent drops and converges to that of the direct exposures (see Figure 5(c)). This convergence of contagion extent is an artifact of the introduction of a large number of small contagions during these years (see Figure 5(a)). As in [21], the separation of contagions into "mild contagions" (when $5-30 \%$ of nodes fail) and "moderate contagions" (when over $30 \%$ of nodes fail) would continue to show significantly higher contagion extents from core node failures with the common asset compared to direct exposures only.

The addition of a common asset results in a significantly larger contagion probability and extent for all years. However, one potential criticism of including a common asset is that it has an extremely homogenizing effect on exposures. Because the asset is truly "common" to all banks, any depreciation in the asset will necessarily weaken the balance sheet of all banks. In addition, without a separate market and pricing structure for this common asset any depreciation must be external and arbitrary. In the next section we introduce a partially overlapping asset or a common asset which only some banks chose to hold (i.e., it is not common to all banks). In addition, we interpret this asset as a fixed ownership portfolio of other banks, which allows us to endogenously devalue this asset following the failure of a bank based on its weight in the portfolio of ownership.

4.3. Partially Overlapping Ownership Asset. In this section we return to the case of direct exposures (i.e., without a common asset) and then add a partially overlapping ownership asset.
Unlike the common asset in Section 4.2, this asset will be held by only some banks (hence "partially overlapping"). We also interpret this asset as reflecting a fixed portfolio of ownership in other banks. For a discussion of this ownership observed in the data see Section 2.2 and of how we implement this ownership in the model see Section 3.2. One of the advantages of interpreting this asset as ownership is that it provides a natural way to devalue the asset following the failure of a bank. With the failure of a bank, the value of ownership in that bank falls to zero and the ownership asset devalues according to share of that bank held in the portfolio.

With the addition of this partially overlapping ownership asset, our main results are a small increase in the probability of a contagion and a large increase in the extent of a contagion stemming from the failure of a core node. As in the case of direct exposures only, contagions do not arise from the failure of a periphery node and figures for an initial periphery failure are omitted. Figure 6 shows the simulated probability of contagion (a) and average extent of contagion (b) based on the failure of a random core node. Included in each figure in red for comparison are the results from Section 4.1 for direct exposures only.

The addition of the partially overlapping ownership asset has a small but positive effect on the probability of a contagion stemming from the failure of a core node (Figure 6(a)). Unlike the case of the common asset in Section 4.2, the partial ownership asset neither consistently depreciates for all failures nor uniformly transmits the this shock to all other banks. For core nodes that are weighted little or not at all in the portfolio, the effect of their failure will be minimal. For example, in 2012, while $91 \%$ of the ownership portfolio was in core banks, three-quarters of this ownership was concentrated in just four of these banks: Bank of America (33\%), Wells Fargo (18\%), SunTrust Banks (10\%), and Citibank (8\%). The effect of a failure of any core bank outside of these four banks would be similar to the case with direct exposures only (i.e., without the partially overlapping ownership asset). Because periphery banks are minimally represented in the ownership asset, the probability of a contagion from the failure of a periphery bank remains at zero, as in Section 4.1.

While the effect of a partially overlapping ownership asset on the probability of a financial contagion may be small, the effect on the average extent of a contagion is relatively large. This is because the ownership portfolio is heavily concentrated in a small number of core node banks. For example, in 2012 the largest shares of ownership by the portfolio are in Bank of America (33\%), Wells Fargo (18\%), SunTrust Banks (10\%), and Citibank (8\%). In the event that one of these banks fails, a contagion due solely to direct exposures is already highly likely and the partially overlapping ownership asset serves as a channel to transmit the contagion to owner-banks who may not have otherwise been affected solely through direct (and indirect) exposures. Ultimately, the partially overlapping ownership asset has the effect of increasing the importance of a select few core banks and worsening the extent of a contagion should one of these banks fail. In the next section we combine this partially overlapping ownership asset with the common asset. 


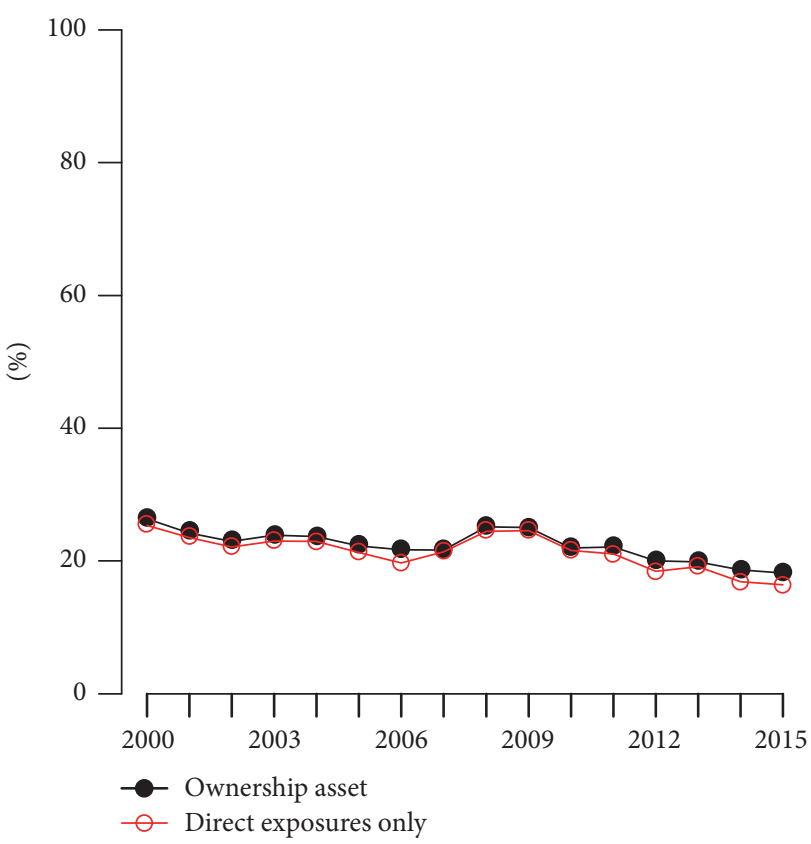

(a) Contagion probability (core node)

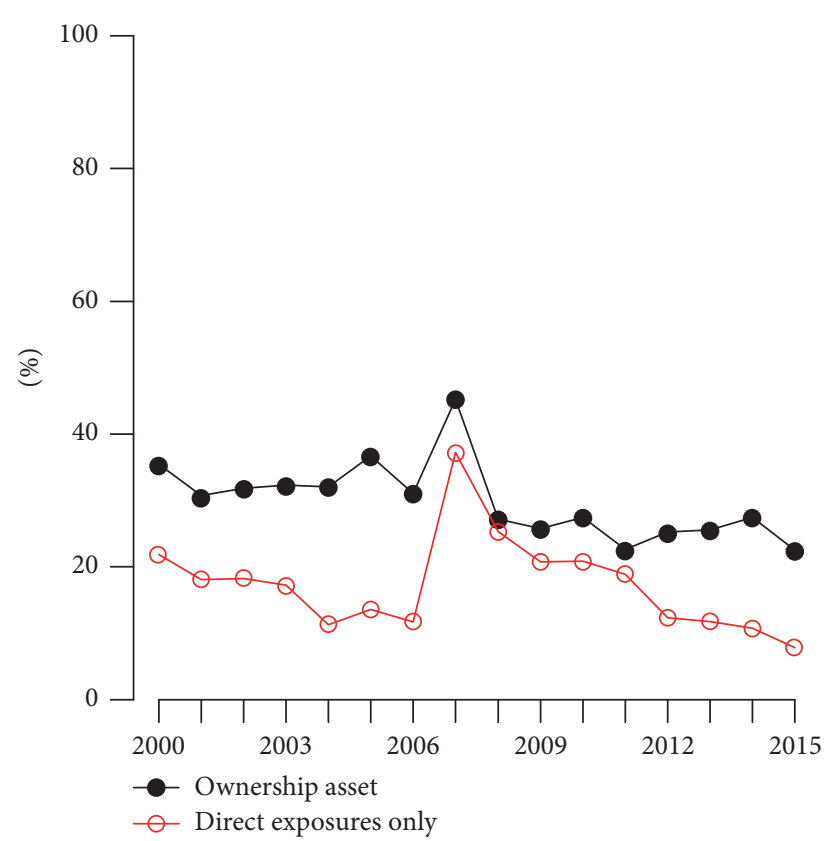

(b) Contagion extent (core node)

FIgure 6: Contagions with a Partially Overlapping Ownership Asset. Probability of a contagion (a) and average extent of contagion (b) for a core-periphery network with a partially overlapping ownership asset and direct exposures (black solid circles) and direct exposures only (red empty circles) conditioned on a random core bank failing.

4.4. Common and Partially Overlapping Ownership Assets. In this section we add both the partially overlapping ownership and common asset to direct exposures. Figure 7 shows the simulated probability of contagion (a) and average extent of contagion (c) based on the failure of a random core node as well as the probability of contagion (b) and average extent of contagion (d) based on the failure of a random periphery node. Included in each figure in red for comparison are the results from Section 4.2 for direct exposures with a common asset.

The addition of the partially overlapping ownership asset with the common asset and direct exposures has similar effects to those outlined in Section 4.3. There is a small increase in the probability of contagion from core nodes in the years prior to and after the financial crisis (Figure 7(a)) and there is a substantial increase in the extent of contagion (Figure 7(b)). There is no significant effect on contagions resulting from periphery node failures. The lack of a significant interaction between the common asset and partially overlapping ownership asset is not surprising given that the first disproportionately affects contagions from periphery node failures while the second disproportionately affects contagions from core node failures. This is primarily the case due to the observed makeup of the ownership asset portfolio which heavily reflects core node banks (e.g., in 2015 over $92 \%$ of the ownership portfolio was in core banks). While the partially overlapping ownership asset is held by many periphery banks, failures from periphery banks have a limited, if any, effect on the value of this asset. If, hypothetically, the ownership asset was constructed primarily of periphery banks the results would be quite different.

\section{Conclusion}

Using historical data on the US banking industry from 2000 to 2015 we calibrate a core-periphery financial network model and characterize the probability and average extent of a financial contagion over time from the random failure of a core or periphery node. The financial network is composed of a network of heterogeneous direct exposures, calibrated to data where possible. In addition to direct exposures we consider two other types of assets. The first is a common asset as in [2] and for the second we introduce a partially overlapping ownership asset to capture the growing equity ownership of banks by banks that we observe in the data. This partially overlapping ownership asset is held by a subset of banks and devalues endogenously based on the failure of banks within the system.

The results show that with direct exposures only, in 2007 and 2008, prior to the US financial crisis, the probability of contagion resulting from the failure of a core bank rose from $19.7 \%$ to $24.6 \%$ (a $24 \%$ increase) and the average extent of a potential contagion more than tripled. The addition of a common asset greatly increases the probability of a contagion in all years, bringing it close to $100 \%$ for core banks between 2008 and 2010 and close to $100 \%$ in 2009 for periphery banks, primarily due to the decline in capital buffers among certain banks in 2009. Adding a common asset also more than doubles the average extent of contagion from a core bank failure. The addition of a partially overlapping ownership asset only slightly increases the probability of contagion from a core bank failure (by about $5 \%$ ) but doubles the extent of a contagion on average across all years. The combination of 


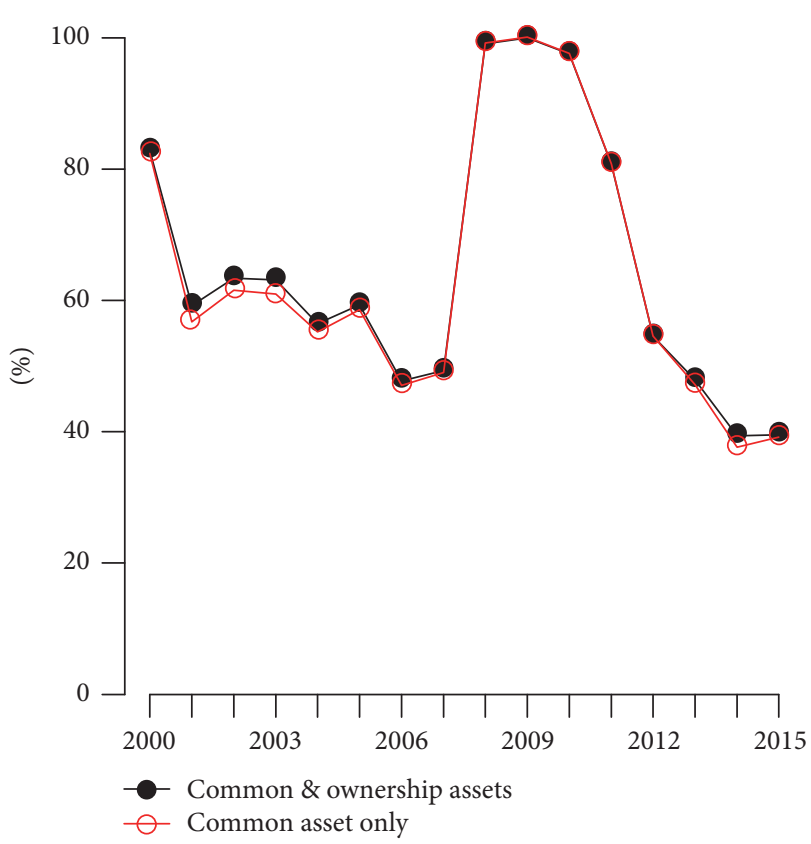

(a) Contagion probability (core node)

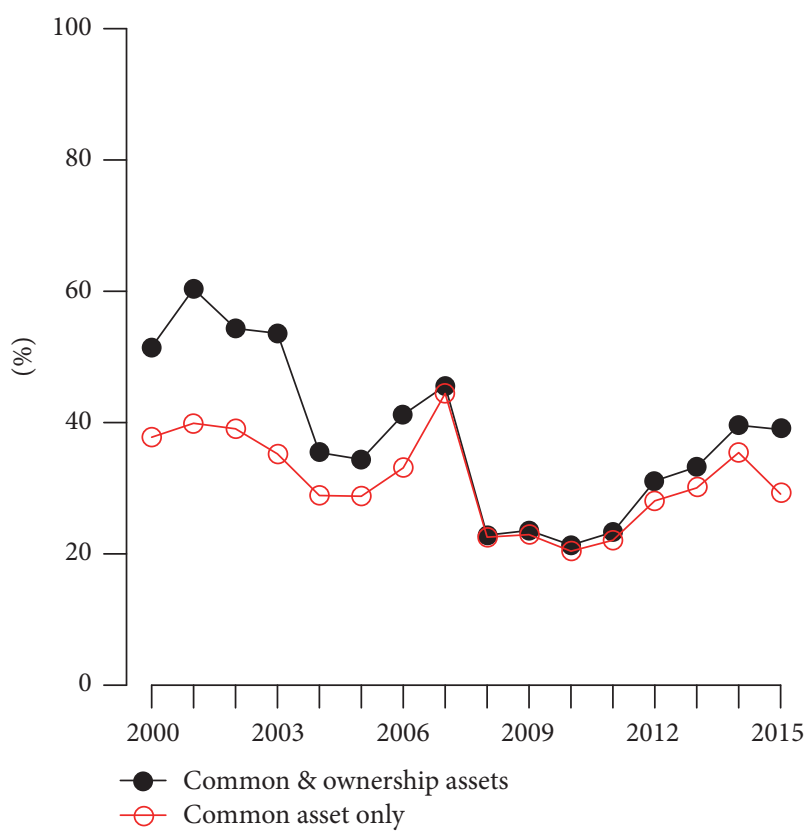

(c) Contagion extent (core node)

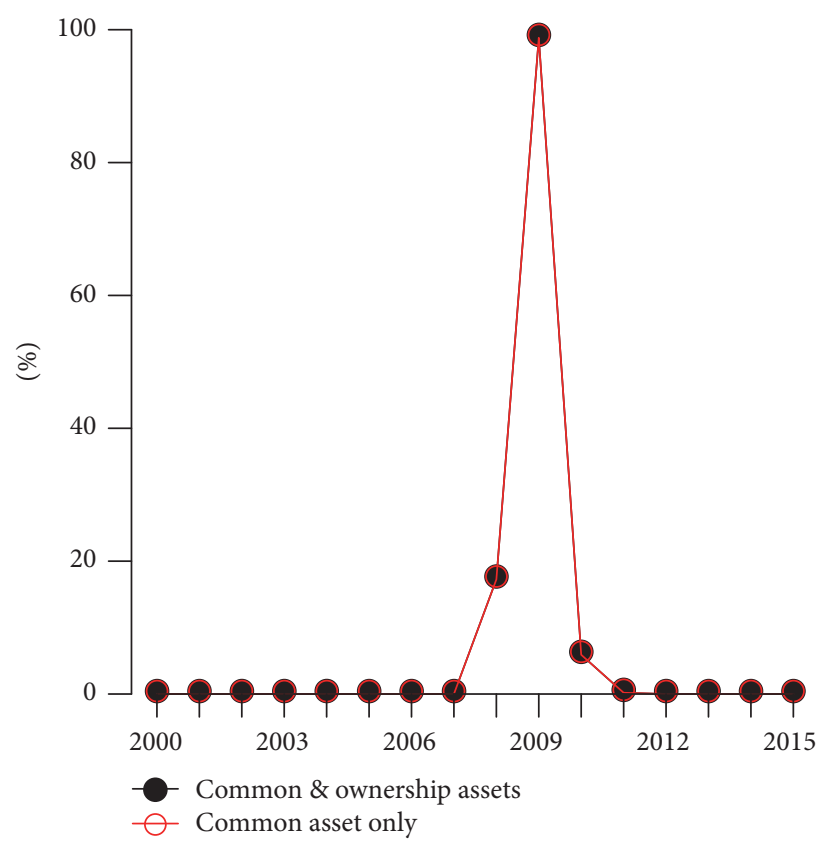

(b) Contagion probability (periphery node)

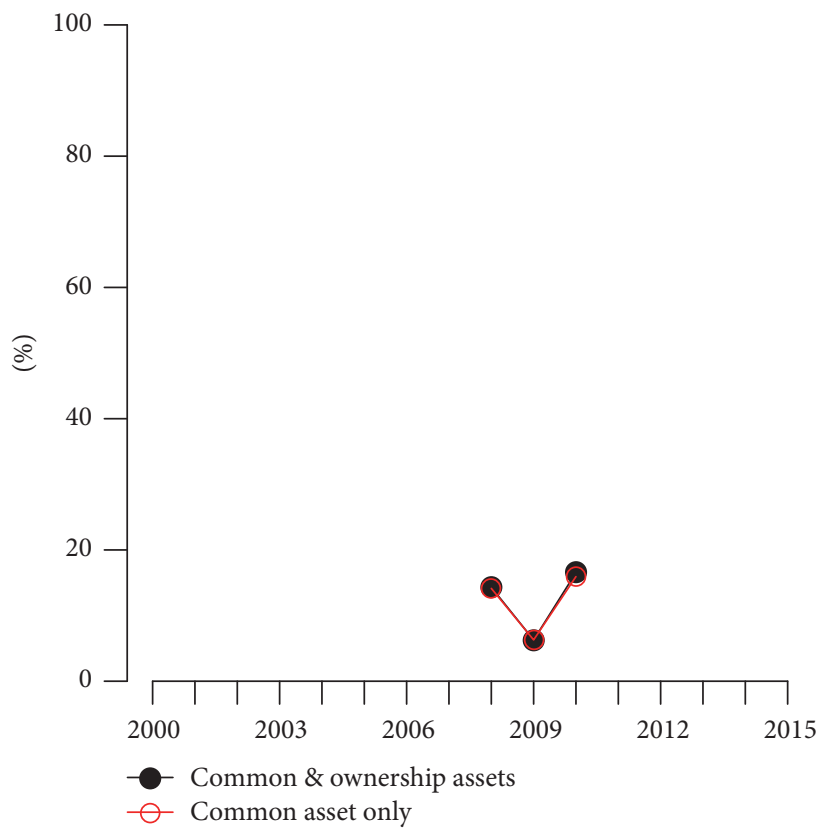

(d) Contagion extent (periphery node)

Figure 7: Contagions with a Partially Overlapping Ownership and Common Asset. Probability of a contagion ((a) and (b)) and average extent of contagion ((c) and (d)) for a core-periphery network with common and partially overlapping ownership assets and direct exposures (black solid circles) and common asset and direct exposures only (red empty circles) conditioned on a random core bank failing ((a) and (c)) and conditioned on a periphery bank failing ((b) and (d)). Contagion extent shown only when average contagion frequency is greater than $1 \%$.

both a common asset and a partially overlapping ownership asset increases both the probability and average extent of a contagion, but there does not appear to be any significant interaction or amplification.

Our data show that many key financial network characteristics, such as number of nodes, total assets, and capital buffers, change significantly over time and these changes have a large effect on the probability and average extent of a potential financial contagion. As a result, researchers may want to consider data from more than a single or small number of years when characterizing a financial network for contagion analysis. A comparison between results from core-periphery networks and scalefree networks (see Appendix B) shows that the differences in probability and average extent of a financial contagion across the two network structures are smaller than the 


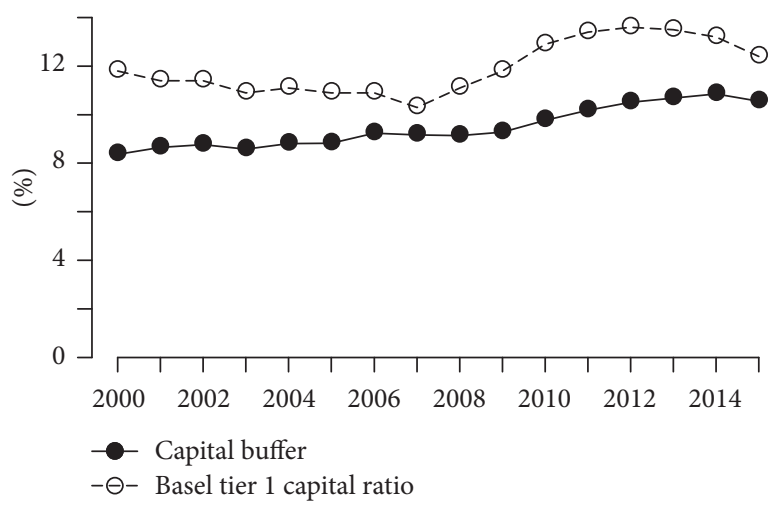

FIGURE 8: Comparison of median capital buffers and median Basel tier 1 capital ratios.

differences across years due to changes in financial network characteristics.

While we interpret equity ownership as investment in a single portfolio asset, such as an index fund of banking stock, a complete network of ownership exposures may also be interpreted as observationally equivalent to a second network, similar to that of interbank lending. In such a case, ownership can be captured by appropriately amplifying the network of interbank exposures. However, there are scenarios in which equity ownership is more appropriately treated as a separate asset from debt. For example, ownership may include the ownership of other firms outside the network of banks (such as insurance or other financial firms) or may reflect more complex types of ownership. In other situations, the order of liquidation in a bankruptcy may be relevant, with interbank debt claims being satisfied prior to, or more wholly than, interbank equity claims. Finally, by its nature, debt typically requires mutual consent to the transaction, while equity does not. There may be a scenario in which one bank deliberately chooses not to borrow from another bank but is unable to prevent this other bank from buying their equity. The distinction between debt and equity become more relevant to the addition of strategic behavior.

In the future we would like to expand this research to look at the effect of partially overlapping ownership assets with other characteristics. For example, if the portfolio was more heavily weighted toward periphery banks then this may increase the probability of contagion more significantly and amplify shocks further once a contagion begins. We would also like to expand the ownership portfolio to include other sources of ownership, such as debt ownership, as well as the ownership of other firms in related financial areas, such as nondepository banks and insurance firms.

Another way to expand this research is to add a dynamic component to the model. For example, if banks in the financial network respond to a first round shock strategically, their response may affect the contagion results. Reference [2] discusses a scenario where banks try to rebalance their portfolio to reach their target leverage level and they conclude that this rebalancing of portfolio destabilizes the system. In contrast, [21] shows that if banks rebalance their portfolio by reducing investment in potentially weakened banks, this rebalancing stabilizes the system to future shocks.

\section{Appendix}

\section{A. Basel Accords}

The definition of capital buffers used in this paper and common in the literature, beginning with [20] and earlier, is of net-worth (total liabilities minus total assets) divided by total assets. This definition is the most literal definition of solvency but does not take into consideration the riskiness of different asset classes. Another interpretation of capital buffers that does consider the riskiness of assets comes from the Basel Accords or the international recommendations on banking regulations. Basel I was developed in 1988 by the Basel Committee on Banking Supervision (BCBS) and was adopted in law by the Unites States and other G-10 countries in 1992. Since then the Basel Accord has gone through revisions (Basel II in 2004 and Basel III in 2010). In the United States Basel II became effective on April 1,2008 , but with some rules initially delayed or waived due the 2007/2008 financial crises. The Basel III recommendations were approved on July 9, 2013, in the United States.

Under the Basel Accords the regulatory capital buffer is measured in part by the tier 1 capital ratio or the ratio of a bank's core equity capital to its total risk-weighted assets. While the tier 1 capital ratio more accurately measures solvency riskiness than actual solvency, it may be useful to compare this measure with the more traditional definition of capital buffers. Figure 8 compares the median capital buffer (as defined in this paper) with the tier 1 capital ratio under the Basel Accord. In all years the tier 1 capital ratio is significantly higher than the capital buffer, reflecting that it accounts for the riskiness of relatively safe or risk-free assets on the balance sheet. Overall the trend we see in the data for tier 1 capital ratios is similar to the trend in capital buffers, other than a sharper decline during the years leading up to the US financial crisis. Another reason we do not use the tier 1 capital ratio in our model is that participation in the Basel Accord was voluntary prior to 2008 (in $200897.1 \%$ of our sample reported tier 1 capital buffers under the Basel Accords, 


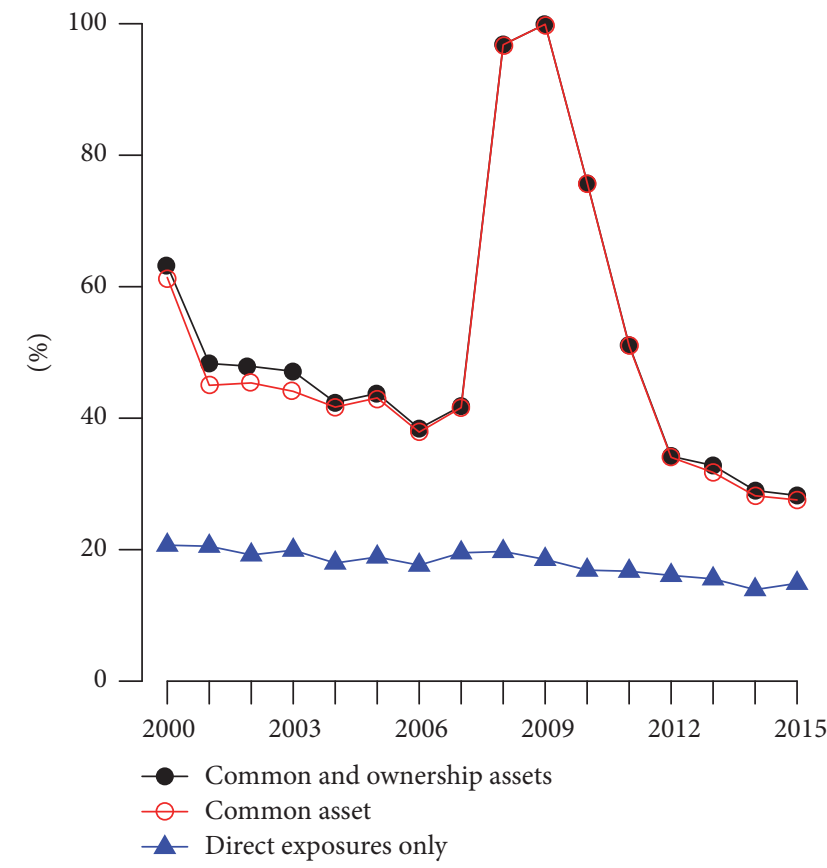

(a) Contagion probability (core node)

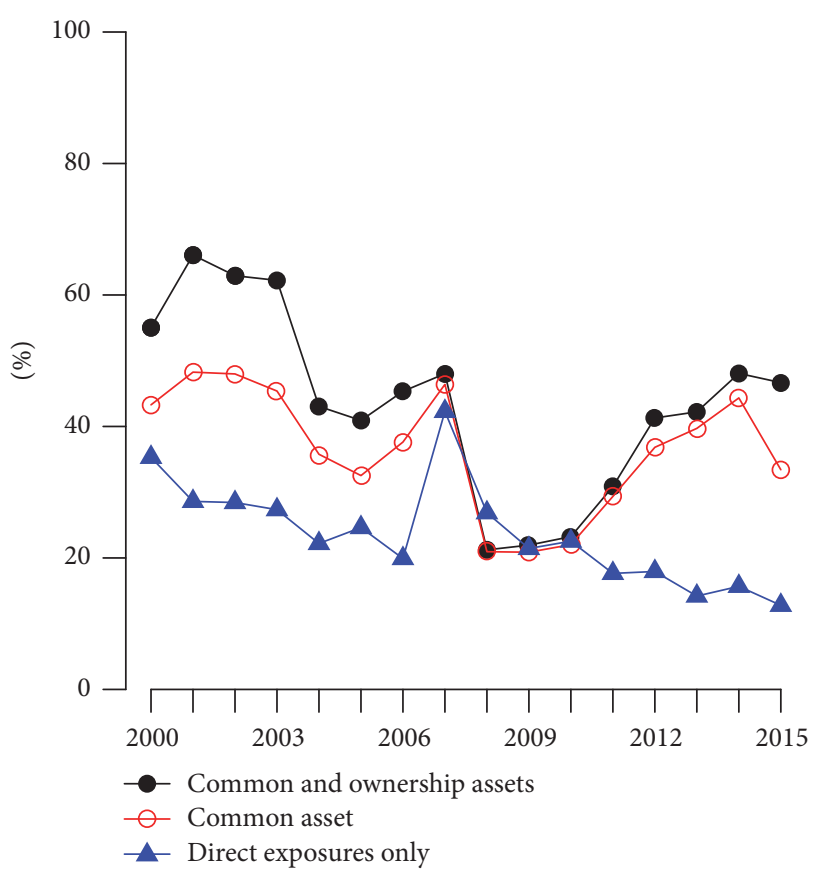

(c) Contagion extent (core node)

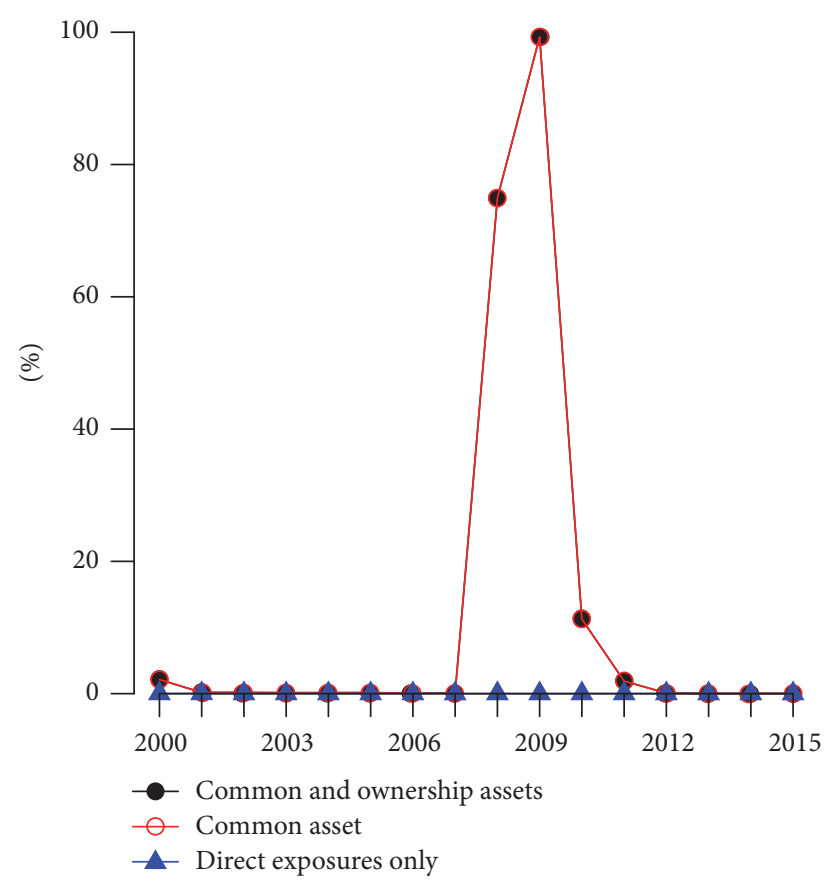

(b) Contagion probability (periphery node)

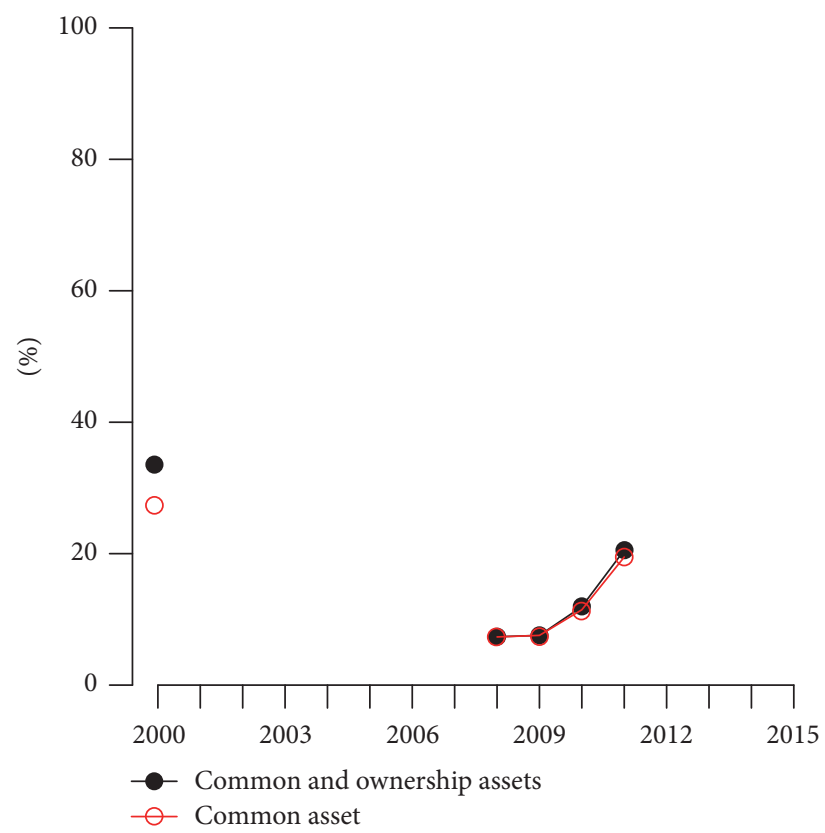

(d) Contagion extent (periphery node)

FIGURE 9: Results for the Scale-Free Network Structure. Probability of a contagion ((a) and (b)) and average extent of contagion ((c) and (d)) for a scale-free network with common and partially overlapping ownership assets and direct exposures (black solid circles), common asset and direct exposures only (red empty circles), and direct exposures only (blue solid triangles), conditioned on a random core bank failing $((\mathrm{a})$ and $(\mathrm{c}))$ and conditioned on a periphery bank failing $((\mathrm{b})$ and $(\mathrm{d}))$. Contagion extent shown only when average contagion frequency is greater than $1 \%$. 
compared to only $62.3 \%$ in 2003 and $6.6 \%$ in 2000), and the rules were further changed in 2010.

\section{B. Results from Scale-Free Network Structure}

For the purpose of comparing our results for the coreperiphery network structure with the commonly used scale-free structure we use Barabási-Albert model to construct a scale-free network, which reflects the preferential attachment characteristic of scale-free networks. The algorithm we use here is a directed version of Barabási-Albert model from Bollobás et al. [23].

Assume that $\alpha, \beta, \gamma, \delta_{\text {in }}$, and $\delta_{\text {out }}$ are nonnegative real numbers such that $\alpha+\beta+\gamma=1$. Starting with an initial graph $G 0=G\left(t_{0}\right)$, we form $G(t+1)$ from $G(t)$ according to the following steps:

(1) With probability $\alpha$, add a new vertex $v$, together with an edge from $v$ to an existing vertex $w$, where $w$ is chosen according to $d_{\text {in }}+\delta_{\text {in }}\left(P\left(w=w_{i}\right)=\right.$ $\left.\left(d_{\text {in }}\left(w_{i}\right)+\delta_{\text {in }}\right) /\left(t+\delta_{\text {in }} n(t)\right)\right)$, where $d_{\text {in }}\left(w_{i}\right)$ represents the incoming degree for node $i$ and $n(t)$ represents the number of vertices in the graph at time $t$.

(2) With probability $\beta$, add an edge from an existing vertex $v$ to an existing vertex $w$, where $v$ and $w$ are chosen independently, $v$ is chosen according to $d_{\text {out }}+$ $\delta_{\text {out }}$, and $w$ is chosen according to $d_{\text {in }}+\delta_{\text {in }}$.

(3) With probability $\gamma$, add a new vertex $w$, together with an edge from an existing vertex $v$ to $w$, where $v$ is chosen according to $d_{\text {out }}+\delta_{\text {out }}$.

To simplify comparisons with the core-periphery network structure, we use the terminology "core node" to refer to the 25 largest nodes (by total assets) in the scale-free model and "periphery node" to refer to other nodes. Figure 9 presents for the scale-free network that are comparable to those of the core-periphery structure presented in Sections 4.1, 4.2, and 4.4. Both network structures yield extremely similar results.

\section{Conflicts of Interest}

The authors declare that there are no conflicts of interest regarding the publication of this article.

\section{References}

[1] M. Chinazzi and G. Fagiolo, "Systemic risk, contagion, and financial networks: a survey," SSRN Electronic Journal, p. 57, 2015.

[2] F. Caccioli, M. Shrestha, C. Moore, and J. D. Farmer, "Stability analysis of financial contagion due to overlapping portfolios," Journal of Banking \& Finance, vol. 46, no. 1, pp. 233-245, 2014.

[3] A. Sensoy, "Firm size, ownership structure, and systematic liquidity risk: the case of an emerging market," Journal of Financial Stability, vol. 31, pp. 62-80, 2017.

[4] F. Caccioli, J. D. Farmer, N. Foti, and D. Rockmore, "Overlapping portfolios, contagion, and financial stability," Journal of Economic Dynamics \& Control, vol. 51, pp. 50-63, 2015.
[5] S. Poledna, J. L. Molina-Borboa, S. Martínez-Jaramillo, M. van der Leij, and S. Thurner, "The multi-layer network nature of systemic risk and its implications for the costs of financial crises," Journal of Financial Stability, vol. 20, pp. 70-81, 2015.

[6] M. Boss, H. Elsinger, M. Summer, and S. Thurner, "Network topology of the interbank market," Quantitative Finance, vol. 4, no. 6, pp. 677-684, 2004.

[7] K. Soramäki, M. L. Bech, J. Arnold, R. J. Glass, and W. E. Beyeler, "The topology of interbank payment flows," Physica A: Statistical Mechanics and its Applications, vol. 379, no. 1, pp. 317333, 2007.

[8] R. Cont, A. Moussa, and E. B. Santos, "Network structure and systemic risk in banking systems," Handbook of Systemic Risk, pp. 327-368, 2013, Network structure and systemic risk in banking systems, Handbook of Systemic Risk.

[9] D. in't Veld and I. van Lelyveld, "Finding the core: network structure in interbank markets," Journal of Banking \& Finance, vol. 49, pp. 27-40, 2014.

[10] D. Fricke and T. Lux, "Core-periphery structure in the overnight money market: evidence from the e-MID trading platform," Computational Economics, vol. 45, no. 3, pp. 359-395, 2014.

[11] B. Craig and G. Von Peter, "Interbank tiering and money center banks," Journal of Financial Intermediation, vol. 23, no. 3, pp. 322-347, 2014.

[12] S. Langfield, Z. Liu, and T. Ota, "Mapping the UK interbank system," Journal of Banking \& Finance, vol. 45, no. 1, pp. 288303, 2014.

[13] T. C. Silva, S. R. S. de Souza, and B. M. Tabak, "Network structure analysis of the Brazilian interbank market," Emerging Markets Review, vol. 26, pp. 130-152, 2016.

[14] M. P. Solis-Montes, "The structure of the Mexican interbank market," Banco de México, 2013.

[15] T. Lux, "Emergence of a core-periphery structure in a simple dynamic model of the interbank market," Journal of Economic Dynamics \& Control, vol. 52, pp. A11-A23, 2015.

[16] M. van der Leij, D. in't Veld, and C. Hommes, The formation of a core periphery structure in heterogeneous financial networks, De Nederlandsche Bank Working Paper No. 528.

[17] A. Galeotti, C. Ghiglino, and S. Goyal, "Financial linkages, portfolio choice and systemic risk," 2016, https://doi.org/10.17863/ CAM.4951.

[18] R. McCord and E. S. Prescott, "The financial crisis, the collapse of bank entry, and changes in the size distribution of banks," FRB Richmond Economic Quarterly, vol. 100, pp. 23-50, 2014.

[19] M. Kowalik, T. Davig, C. S. Morris, and K. Regehr, "Bank consolidation and merger activity following the crisis," Economic Review-Federal Reserve Bank of Kansas City, pp. 31-49, 2015.

[20] P. Gai and S. Kapadia, "Contagion in financial networks," Proceedings of the Royal Society A Mathematical, Physical and Engineering Sciences, vol. 466, no. 2120, pp. 2401-2423, 2010.

[21] Y. Guan and M. Pollak, "Contagion in heterogeneous financial networks," Advances in Complex Systems, vol. 19, no. 1-2, Article ID 1650001, p. 25, 2016.

[22] F. Caccioli, T. A. Catanach, and J. D. Farmer, "Heterogeneity, correlations and financial contagion," Advances in Complex Systems, vol. 15, no. supplement 2, Article ID 1250058, p. 15, 2012.

[23] B. Bollobás, C. Borgs, J. Chayes, and O. Riordan, "Directed scale free graphs," in Proceedings of the Fourteenth Annual ACMSIAM Symposium on Discrete Algorithms, pp. 132-139, 2003. 


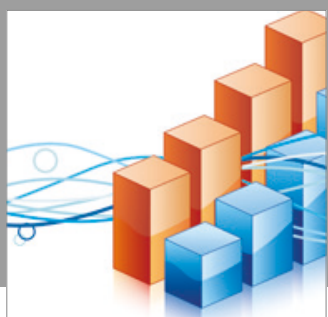

Advances in

Operations Research

vatersals

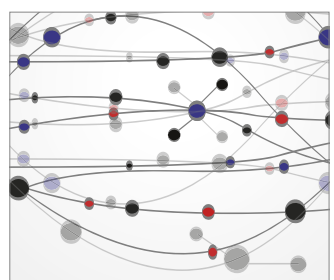

\section{The Scientific} World Journal
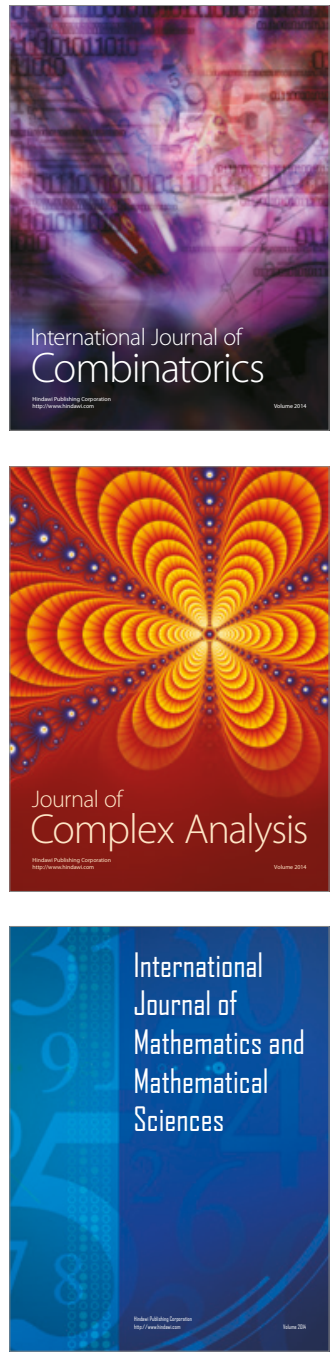
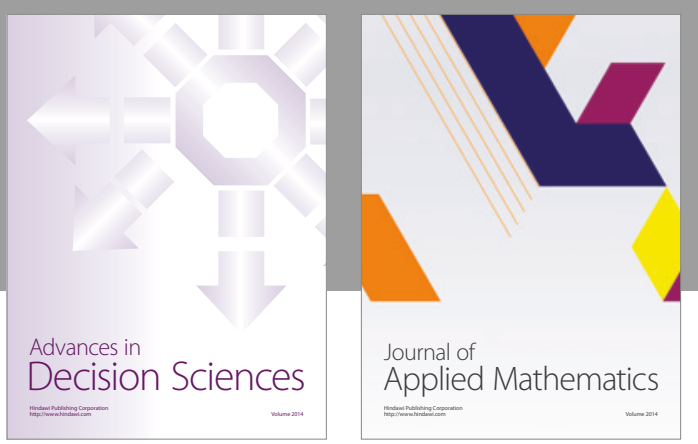

Algebra

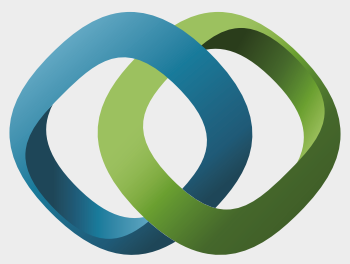

\section{Hindawi}

Submit your manuscripts at

https://www.hindawi.com
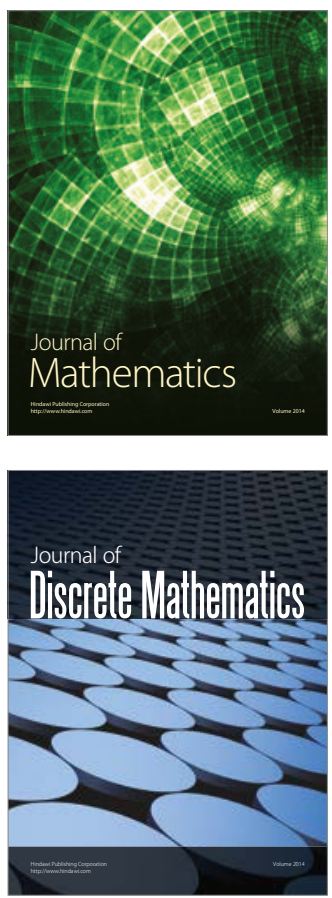

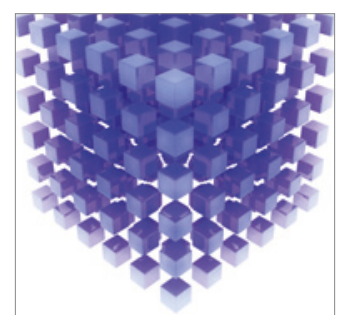

Mathematical Problems in Engineering
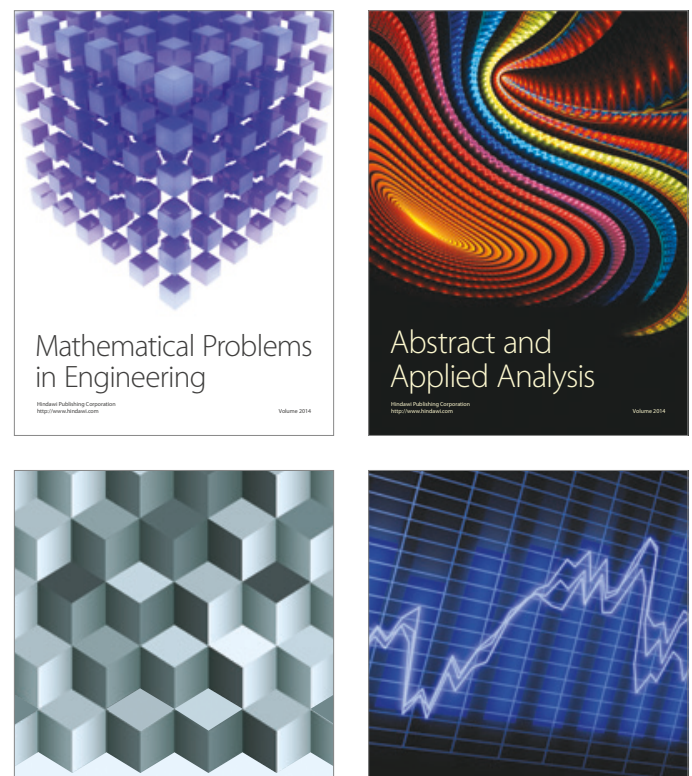

Journal of

Function Spaces

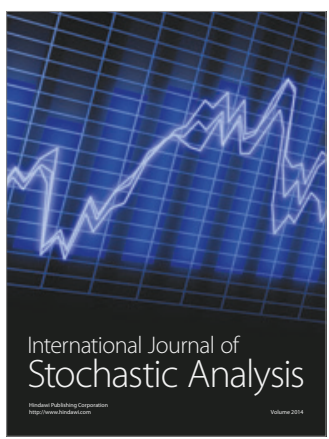

Probability and Statistics
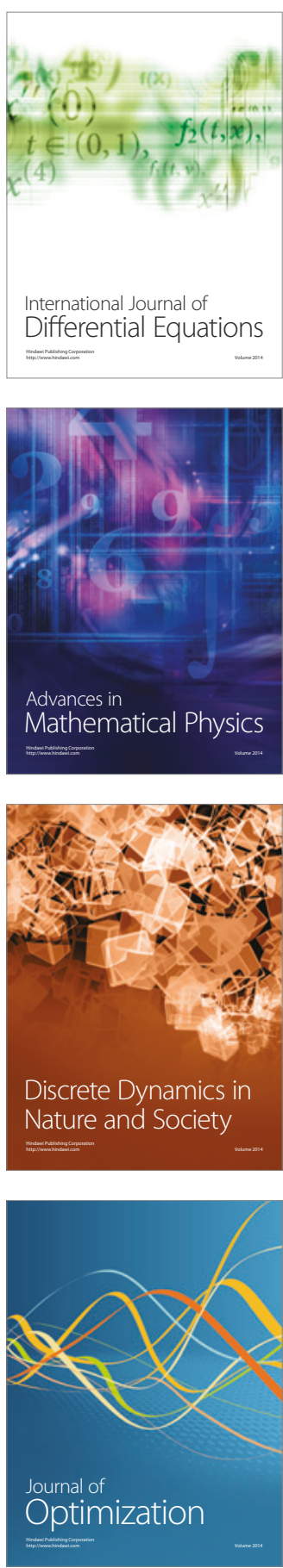